Research Discussion Paper

RDP 2021-11

\title{
Smells Like Animal Spirits: The Effect of Corporate Sentiment on Investment
}

Gianni La Cava

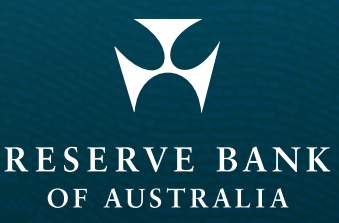


The Discussion Paper series is intended to make the results of the current economic research within the Reserve Bank of Australia (RBA) available to other economists. Its aim is to present preliminary results of research so as to encourage discussion and comment. Views expressed in this paper are those of the authors and not necessarily those of the RBA. However, the RBA owns the copyright in this paper.

(c) Reserve Bank of Australia 2021

Apart from any use permitted under the Copyright Act 1968, and the permissions explictly granted below, all other rights are reserved in all materials contained in this paper.

All materials contained in this paper, with the exception of any Excluded Material as defined on the RBA website, are provided under a Creative Commons Attribution 4.0 International License. The materials covered by this licence may be used, reproduced, published, communicated to the public and adapted provided that there is attribution to the authors in a way that makes clear that the paper is the work of the authors and the views in the paper are those of the authors and not the RBA.

For the full copyright and disclaimer provisions which apply to this paper, including those provisions which relate to Excluded Material, see the RBA website.

Enquiries:

Phone: +61295519830

Facsimile: +61295518033

Email: rbainfo@rba.gov.au

Website: https://www.rba.gov.au

Figures in this publication were generated using Mathematica. 


\title{
Smells Like Animal Spirits: The Effect of Corporate Sentiment on Investment
}

\author{
Gianni La Cava \\ Research Discussion Paper \\ 2021-11
}

November 2021

Economic Research Department

Reserve Bank of Australia

I would like to thank Amanda Martz, Laura Nowzohour, Matthew Read, John Simon and Callan Windsor and seminar participants at the Reserve Bank of Australia and Macquarie University for their helpful comments. I am especially indebted to Jessica Boyle, Vienna Lu and Kim Nguyen for their feedback and technical help in undertaking the text analysis. And I am forever indebted to Paula Drew for her patience, advice and editing over the past 20 years. The views expressed in this paper are those of the author and do not necessarily reflect the views of the Reserve Bank of Australia. The author is solely responsible for any errors.

Author: giannilacava at domain gmail.com

External Communications: rbainfo@rba.gov.au

https://doi.org/10.47688/rdp2021-11 


\begin{abstract}
Economists have long been interested in the effect of business sentiment on economic activity. Using text analysis, I construct a new company-level indicator of sentiment based on the net balance of positive and negative words in Australian company disclosures. I find that company-level investment is very sensitive to changes in this corporate sentiment indicator, even controlling for fundamentals, such as Tobin's $\mathrm{Q}$ and expected profits, as well as controlling for measures of company-level uncertainty.

I explore the mechanisms that link investment to sentiment. The conditional relationship could be because sentiment proxies for private information held by managers about the future prospects of the company or because of animal spirits among managers relative to investors. I find that the effect of sentiment on investment is relatively persistent, which is consistent with the private information story, albeit less persistent than other news shocks, such as Tobin's Q. But the effect of sentiment on investment is not any stronger at 'opaque' companies in which managers are likely to be better informed than investors, which argues against the private information story.

Corporate investment has been weak in Australia since the global financial crisis (GFC) and demand-side factors, such as lower sales growth, explain more than half this persistent weakness. Low sentiment and heightened uncertainty weighed on investment during the GFC but have been less important factors since then.
\end{abstract}

JEL Classification Numbers: D22, D25, D84, D91, E22, E71

Keywords: investment, sentiment, text analysis, animal spirits, business cycle 


\section{Table of Contents}

1. Corporate Sentiment, Animal Spirits and Investment 1

2. The Tobin's Q Model with Sentiment Shocks 6

3. Company-level Information on Sentiment and Investment 8

3.1 Company-level sentiment 8

3.2 Company-level investment and fundamentals 11

3.3 Publicly listed company sample 12

3.4 Information sets of company managers and investors 12

3.5 Summary statistics 13

4. The Effect of Corporate Sentiment Shocks 14

4.1 The distribution of sentiment and investment 14

4.2 The effect of sentiment on investment 15

4.3 The dynamics of corporate sentiment, uncertainty and investment 17

5. Robustness Tests and Extensions $\quad 19$

5.1 Why does corporate sentiment matter to investment? 19

5.1.1 Private knowledge of company managers 19

$\begin{array}{lll}5.1 .2 & \text { Positive versus negative sentiment } & 21\end{array}$

5.2 The measurement of corporate fundamentals 22

5.2.1 Measurement error in corporate fundamentals and sentiment 22

5.2.2 Alternative measures of corporate fundamentals 24

5.3 Corporate sentiment and business surveys 25

5.4 Explaining the post-GFC weakness in investment 26

$\begin{array}{ll}\text { 6. Policy Implications and Conclusions } & 27\end{array}$

$\begin{array}{lr}\text { References } & 29\end{array}$

$\begin{array}{ll}\text { Copyright and Disclaimer Notice } & 31\end{array}$ 



\section{Corporate Sentiment, Animal Spirits and Investment}

'We should not conclude from this that everything depends on waves of irrational psychology ... We are merely reminding ourselves that human decisions affecting the future, whether personal or political or economic, cannot depend on strict mathematical expectation, since the basis for making such calculations does not exist; and that it is our innate urge to activity which makes the wheels go round ...' (Keynes 1936, pp 162-163)

Economists have long been interested in the role of 'animal spirits' (or sentiment) in the business cycle. Since Keynes (1936) originally coined the term 'animal spirits' there have been many books written on the subject and an extensive literature in economics, finance and psychology has grown to study how changes in sentiment amongst individual decision-makers affect their behaviour and, in turn, the overall economy.

But identifying a role for sentiment in the business cycle is challenging partly because it is hard to define. Economists have long recognised the importance of expectations for aggregate economic behaviour, but they disagree on why expectations matter and how expectations are formed. Such disagreements make it difficult to define sentiment. For example, Keynes (1936) argued that changes in expectations were not caused by rational probabilistic calculations but by animal spirits, and Pigou (1927) similarly believed that business cycles were largely driven by expectation errors of optimism and pessimism. ${ }^{1}$ Expectations are important in modern general equilibrium models, but they are typically modelled according to the rational expectations hypothesis. Some rational expectations models allow for animal spirits by assuming equilibrium indeterminancy - expectation errors are a function of structural disturbances and exogenous 'sunspot' variables (Benhabib and Farmer 1999). Similarly, in this paper, I define changes in sentiment as shifts in expectations that are exogenous to changes in economic fundamentals (Milani 2017).

Identifying a role for sentiment is also challenging because it is not observed. Traditionally, economists have relied on surveys of consumers and businesses to measure sentiment. These surveys ask respondents about their beliefs for current and future economic conditions. But advances in machine learning and big data have allowed sentiment to be measured not just through surveys, but through alternative sources of information, such as text, audio and visual data (Algaba et a/2020). These techniques present new opportunities to measure sentiment and therefore answer long-standing questions about the role of sentiment in the business cycle.

In practice, it is also difficult to disentangle the effects of sentiment and uncertainty. Assuming that business managers have different expectations about future growth outcomes, sentiment can be thought of as the average outcome (the first moment of the distribution) while uncertainty can be thought of as the variance of possible outcomes (the second moment). ${ }^{2}$ A negative sentiment shock would cause firms to expect average growth to fall. A negative uncertainty shock would lead firms

1 The Macquarie Dictionary defines sentiment as 'a thought influenced by or proceeding from feeling or emotion'. This suggests that sentiment should be defined in terms of the strength of feeling that agents hold in predicting future outcomes.

2 In the paper I assume that 'sentiment' and 'confidence' are the same concept, even though it may be possible to distinguish between 'sentiment' as referring to beliefs about current economic conditions and 'confidence' referring to beliefs about future economic conditions. 
to believe that a broader range of growth outcomes is possible. For example, recessions are typically associated with both a decline in average sales growth and a higher variance (Figure 1).

Figure 1: Distribution of Company-level Sales Growth 2002/03 to 2019/20, annual

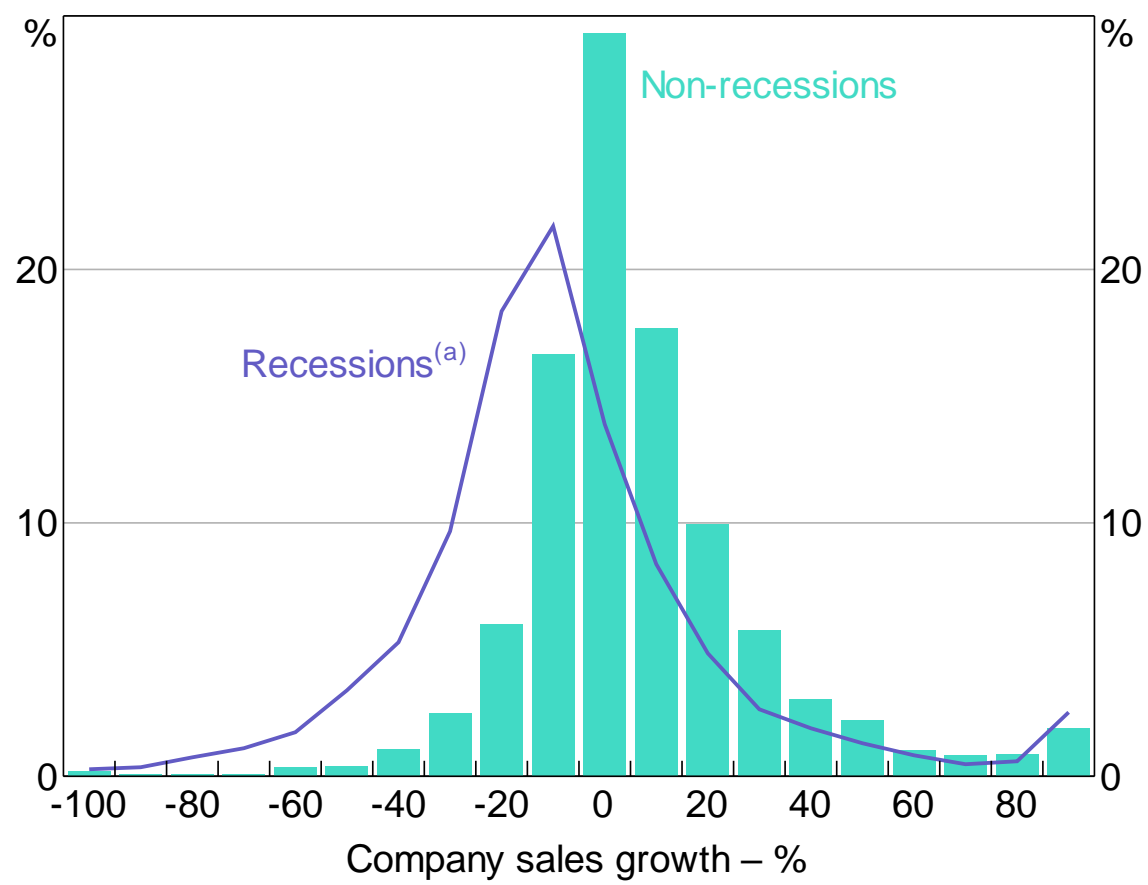

Note: (a) Data are based on the three financial years of 2008/09, 2009/10 and 2019/20

Sources: Author's calculations; Morningstar

Motivated by these insights, I construct a new indicator of company-level sentiment using text analysis and examine its link to the business cycle by identifying how changes in company-level sentiment are associated with changes in investment. The measure of sentiment is very simple and is constructed as the net balance of positive and negative words used in the annual reports of publicly listed companies in Australia. A company that uses more positive words (or fewer negative words) in its report compared to the previous report is higher in sentiment and therefore more likely to invest, all other things being equal.

This paper aims to extend insights from text-based analysis of sentiment in behavioural finance to the domain of macroeconomics. While text analysis is relatively new in macroeconomics, it is much more common in corporate finance (Kearney and Liu 2014). In standard corporate finance models there is no role for sentiment in explaining corporate behaviour. But the behavioural finance literature has consistently found that text-based measures of sentiment for investors (Zhou 2018) and managers (Jiang at a/2019) have strong ability to predict equity returns. I explore whether such measures also have predictive ability for corporate investment - a key variable of interest to macroeconomists.

The focus on business investment is motivated by the observation that much of the variation in the business cycle is due to fluctuations in investment. If there is a role for sentiment in explaining economic activity, it is likely to be found in its link to business investment. The literature has long recognised the importance of business expectations in models of investment under uncertainty 
(e.g. Hayashi 1982; Abel and Blanchard 1986; Chirinko 1993; Dixit and Pindyck 1994). But open questions remain, such as why expectations matter to investment, and whether there is a role for feelings or opinions (and hence sentiment) in influencing such decision-making. This paper explicitly examines such roles for sentiment and uncertainty.

An added motivation of this paper is to explore whether sentiment and uncertainty have some role to play in explaining the broad-based weakness in business investment observed since the global financial crisis (GFC). It is common to hear financial market participants, business managers and the media argue that this weakness in investment is at least partly due to 'a lack of confidence' or 'heightened uncertainty'. The weakness in investment is apparent in both Australia and the United States. It is also apparent for both aggregate investment (in the national accounts) and for the investment of the average small business (in firm-level data) (Figure 2 ). ${ }^{3}$ The fact that it is so prevalent points to common causes across countries and industries. Even so, there remains a long list of potential explanations for the weakness in investment (Gutiérrez and Philippon 2017).

Figure 2: Non-mining Business Investment in Australia

Share of gross value added

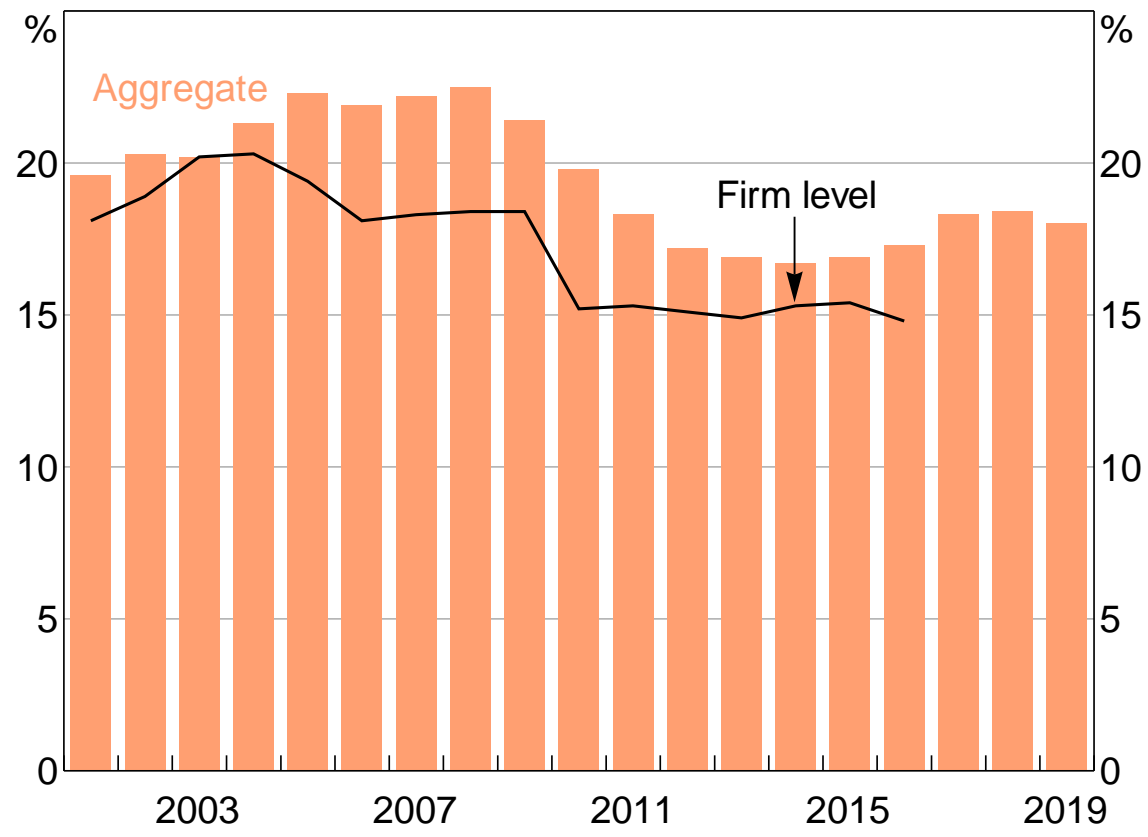

Note: $\quad$ The aggregate series is measured as the ratio of private business investment to total value added for non-mining industries in the national accounts and the firm level series is an unweighted mean of the capital spending to value added ratio at the firm level

Sources: ABS; Author's calculations

This paper fits into a growing literature that examines the role of both news (fundamentals) and sentiment (non-fundamentals) in driving the business cycle. This literature is divided about the role of sentiment in explaining changes in macroeconomic conditions (Nowzohour and Stracca 2020). There is the 'fundamental' view that believes that measures of sentiment capture news about the economy (e.g. Roberts and Simon 2001; Barsky and Sims 2012; Blanchard, L'Huillier and Lorenzoni 2013; Beaudry and Portier 2014). Under this view, agents receive an imperfect signal

3 The firm-level investment data shown in Figure 2 are based on estimates for the entire population of Australian businesses and are drawn from the ABS BLADE data environment. 
about future economic fundamentals, such as productivity, and the economy is subject to recurrent booms (if the signal is correct) and occasional busts (if the signal is false). There is also the 'animal spirits' view that measures of sentiment capture non-fundamental factors (e.g. Akerlof and Shiller 2009; Farmer 2012; Benhabib, Wang and Wen 2015). This line of research argues that psychological waves of optimism and pessimism cause macroeconomic fluctuations, implying that expansions eventually lead to busts as fundamentals are unaffected.

This paper is also related to a vast body of empirical research that studies the effects of uncertainty on the economy (e.g. Bloom 2009). Most of the existing literature focuses on identifying the effect of either sentiment or uncertainty and it is surprisingly rare to see them considered side by side. A key contribution of this paper is to develop an empirical framework in which to measure both sentiment and uncertainty on a consistent basis using text analysis. This allows me to test for differential effects of sentiment and uncertainty on investment, which may be important to understanding the drivers of the business cycle.

I motivate my empirical approach to identifying the effects of sentiment by considering a standard theoretical model of investment that is extended to allow for sentiment shocks. In this set-up, corporate investment is a function of both current and expected future profits, where the relevant expectations are those of corporate managers, which can differ from market (or investor) expectations. Expected profit growth among corporate managers is based on their beliefs about fundamentals and non-fundamental 'noise' or sentiment shocks.

I find strong evidence that changes in corporate sentiment are positively associated with investment. An increase in one standard deviation of the sentiment indicator is associated with the investment rate increasing from a sample mean of 10 per cent to 16 per cent, all other things being equal. Moreover, the relationship holds even when controlling for a broad range of proxies for corporate fundamentals, including the Tobin's Q ratio, current and expected profitability and sales growth. This suggests that the relationship between sentiment and investment is at least partly capturing the effect of noise shocks, or animal spirits, among managers.

The claim that the effect of sentiment on investment is due to animal spirits rests on the assumption that the sentiment indicator is a pure measure of animal spirits among company managers. But managers may know more about the company's fundamentals than outside investors. If managers have private knowledge about the company's prospects, the relationship between investment and sentiment may be due to fundamental factors, rather than animal spirits.

To test this, I examine whether investment is sensitive to changes in sentiment, even when investors potentially know more about the future of the company than the managers. In particular, I measure Tobin's $Q$ based on the share price at the end of the relevant financial year and I measure sentiment using financial reports from the prior financial year. In this case, investors should have incorporated any relevant information revealed about the company's future prospects from the relevant corporate reports. But, even with this timing advantage, I find that investment is still more sensitive to lagged sentiment than it is to Tobin's Q.

I also explore heterogeneity in the sensitivity of investment to sentiment across companies. If the sentiment indicator is mainly capturing private knowledge among managers, investment should be more sensitive to sentiment in companies that are more opaque to outside investors. This might 
include companies that are small or new or that have shares that are rarely traded. However, I find that the sentiment effect is not stronger for small, young or rarely traded companies, which argues against the private knowledge interpretation.

To further explore the mechanism underpinning the sensitivity of investment to sentiment, I also explore the dynamics of investment in response to shocks to sentiment, uncertainty and Tobin's Q through a series of local projections. This identification strategy assumes that sentiment will have a temporary effect on investment if it mainly reflects animal spirits, whereas it should have a more permanent effect if it reflects fundamentals (Barsky and Sims 2012). Here, I find mixed evidence. A sentiment shock has a fairly persistent effect on investment, though the effect is more temporary than that of an equivalent shock to Tobin's Q. I also find that uncertainty shocks have a temporary negative effect on investment of a slightly smaller magnitude to that of a sentiment shock. Overall, I conclude that the sensitivity of investment to sentiment reflects both animal spirits and fundamentals.

The main contributions of this paper are to:

- develop new firm-level indicators of corporate sentiment and uncertainty within the same empirical framework using text analysis;

- demonstrate that firm-level investment is very sensitive to changes in sentiment, even controlling for corporate fundamentals;

- show that both corporate sentiment and uncertainty have independent roles to play in explaining business investment, suggesting that both first and second moment shocks matter;

- show that the effect of sentiment is relatively persistent, albeit more temporary than that of a shock to Tobin's Q, which suggests that the sentiment measure is at least partly capturing animal spirits or noise shocks.

These findings are important from a policy perspective. If sentiment shocks can affect corporate behaviour independently of fundamentals, this suggests that there may be a role for policy to manage business cycle fluctuations by influencing the expectations of corporate managers. So having a variety of policy communication channels that target business decision-makers could matter, including speeches, business liaison programs and surveys dedicated to measuring the beliefs and uncertainties of respondents.

More generally, the ability of simple text-based indicators to consistently predict investment - a macro variable that is inherently difficult to forecast - is consistent with similar findings for equity returns in the corporate finance literature. Based on this, macro policymakers should consider investing more resources in machine learning techniques and extracting information from non-traditional sources of data, such as text, audio and visual media. 


\section{The Tobin's Q Model with Sentiment Shocks}

I motivate my empirical approach to identifying the effect of sentiment on investment by outlining a simple extension to a basic Tobin's Q model. The outline closely follows the descriptions in Blundell et al (1992) and Bond and Cummins (2001).

A representative company optimally chooses investment to maximise the present value of the stream of current and expected future profits. The firm's objective is to maximise:

$$
V_{t}=E_{t} \sum_{s=0}^{\infty} \beta_{t+s} \Pi_{t+s}
$$

where the expected valuation $\left(V_{t}\right)$ of the company is a function of profits in each period $\left(\Pi_{t+s}\right)$ and a discount factor $\left(\beta_{t+s}\right)$. Corporate profits are assumed to have the form:

$$
\Pi_{t}=p_{t} Y\left(K_{t}, N_{t}\right)-w_{t} N_{t}-p_{t}^{K}\left[I_{t}+G\left(I_{t}, K_{t}\right)\right]
$$

where profits in the current period equal the difference between revenue and costs. Revenue is a function of production, which in turn depends on both the capital stock $\left(K_{t}\right)$ and labour $\left(N_{t}\right)$. Costs consist of both labour and capital costs, including capital adjustment costs $\left(G\left(I_{t}, K_{t}\right)\right)$. The capital stock evolves according to the law of motion:

$$
K_{t+s}=I_{t+s}+(1-\delta) K_{t+s-1}
$$

where the capital stock at the end of period $t+s\left(K_{t+s}\right)$ depends on investment during the period $t+s\left(I_{t+s}\right)$ as well as the capital stock outstanding from the end of the previous period $t+s-1$ $\left(K_{t+s-1}\right)$.

The firm chooses investment to maximise the company's expected valuation subject to the capital stock law of motion. The first order conditions (FOCs) for investment are:

$$
\begin{gathered}
\lambda_{t}=-\frac{\partial \Pi_{t}}{\partial I_{t}} \\
\lambda_{t}=E_{t}\left[\sum_{s=0}^{\infty} \beta_{t+s}(1-\delta)^{s}\left(\frac{\partial \Pi_{t+s}}{\partial K_{t+s}}\right)\right]
\end{gathered}
$$

where the shadow value of an additional unit of capital is $\lambda_{t}$. Given price-taking behaviour, the first of the FOCs can be written:

$$
q_{t}-1=\frac{\partial G_{t}}{\partial I_{t}}
$$


Here, marginal $\mathrm{q}\left(q_{t}\right)$ is equal to the ratio of the shadow value of an additional unit of capital to its purchase cost $\left(\lambda_{t} / p_{t}^{K}\right)$. Under certain conditions (such as constant returns to scale and price taking), marginal q can be approximated by average q:

$$
q_{t}=\frac{V_{t}}{p_{t}^{K}(1-\delta) K_{t-1}}
$$

Adjustment costs are assumed to have a symmetric quadratic form:

$$
G\left(I_{t}, K_{t}\right)=\frac{b}{2}\left[\left(\frac{I_{t}}{K_{t}}\right)-c-e_{t}\right]^{2} K_{t}
$$

where adjustment costs depend on the investment rate, a fixed cost component and an idiosyncratic adjustment cost shock $\left(e_{t}\right)$. From this, the Tobin's $\mathrm{Q}$ model of investment can be derived:

$$
\begin{aligned}
\left(\frac{I_{t}}{K_{t}}\right) & =c+\frac{1}{b}\left(\frac{V_{t}}{p_{t}^{k}(1-\delta) K_{t-1}}-1\right)+e_{t} \\
& =c+\frac{1}{b}\left(q_{t}-1\right)+e_{t}
\end{aligned}
$$

In which the error term $\left(e_{t}\right)$ is the adjustment cost shock, observed by the firm but not by the researcher. Adjustment cost shocks are assumed to be white noise (although the key empirical results are not affected if we assume there is serial correlation in the error term).

Now assume that the company owners (or managers) can have different expectations to the market about the future value of the company. Suppose, in particular, that the company's expected valuation, which is equivalent to the valuation of the company's managers $\left(V_{t}\right)$ is equal to the valuation of investors (as measured by the stock market) $\left(\Psi_{t}\right)$ and company-specific sentiment or noise shocks $\left(\mu_{t}\right)$ that have a mean of zero and variance of $\sigma_{\mu}^{2}$ :

$$
V_{t}=\Psi_{t}+\mu_{t}
$$

Here, I assume that the managers of the company can observe the share price and factor this into their own valuation. The managers' valuation of the company is also affected by sentiment shocks that reflect changes in manager expectations that are exogenous to company fundamentals. (This assumes a certain timing structure of information that will be discussed in more detail later.)

Alternative explanations for a difference in the expected valuations of managers and investors are possible. For example, the managers may know more about the fundamentals of the company than shareholders, in which case there will be some fundamental component to the sentiment shocks. This would imply that the sentiment shocks are not pure noise. I test for the possibility of private knowledge in an extension to the baseline model. Alternatively, managers and investors may have different discount factors ( $\beta_{t+s}$ ) with which they value future profits. For instance, managers may have extrapolative expectations about future investment, and the weight they place on future profits differs from those of investors (Gennaioli, Ma and Shleifer 2016). 
This assumption implies that the average q ratio can be written:

$$
q_{t}=\frac{\Psi_{t}+\mu_{t}}{p_{t}^{k}(1-\delta) K_{t-1}}
$$

The average $\mathrm{q}$ ratio is a function of the market equity value (as measured by the stock market) $\left(\psi_{t}\right)$ and sentiment shocks $\left(s_{t}\right)$ :

$$
q_{t}=\psi_{t}+\frac{\mu_{t}}{p_{t}^{k}(1-\delta) K_{t-1}}=\psi_{t}+s_{t}
$$

The following model can therefore be estimated:

$$
\left(\frac{I_{t}}{K_{t}}\right)=c+\frac{1}{b}\left(\psi_{t}-1\right)+\frac{1}{b}\left(s_{t}\right)+e_{t}
$$

where the rate of investment is a function of a standard measure of Tobin's Q (based on equity values) and corporate sentiment shocks. Equation (1) forms the baseline model which I take to the data and test the relationship between corporate investment, sentiment and fundamentals.

\section{Company-level Information on Sentiment and Investment}

\subsection{Company-level sentiment}

There are two general approaches for quantifying sentiment in text - the dictionary- (or lexicon-) and the machine learning-based approaches. The dictionary-based approach relies on predefined lists of words with each word either classified as positive, negative or neutral. The machine learning approach predicts sentiment of any given set of text after training models with a large set of text that has been assigned sentiment ratings by human readers. For example, models have been developed using social media data, such as Twitter, that provide text that is combined with user feedback to identify the sentiment of the posts. This approach is better able to capture the nuances in human language but it is more complex and less transparent (Huang and Simon 2021).

I follow the dictionary-based approach to construct company-level indicators of sentiment and uncertainty. The method is simple and intuitive and has been demonstrated to be sufficient to be able to predict equity returns at the company level. The sentiment indicator measures the net balance of words used in company reports that are considered to be 'positive' and 'negative'. When companies use more positive words and/or fewer negative words, this is an indicator that sentiment at the company has increased. The uncertainty indicator measures the share of uncertain words used (e.g. 'uncertain' and 'risk'). 
I rely on the Loughran and McDonald (2011) (hereafter LM) dictionary of predefined positive, negative and uncertain words that is specially designed for economics and finance. The Harvard Dictionary produces many different word lists, including positive words, negative words, and uncertain words. But nearly three-quarters of the words identified as 'negative' by the Harvard Dictionary are words that are not considered negative in business terminology. For example, the words 'taxes' and 'debt' are not necessarily negative in the context of economics. Similarly, the word 'credit' is not necessarily a positive word.

LM develop alternative word lists that better reflect tone in business terminology. For example, they identify close to 2,500 negative words. Some of the most common negative words that appear in company reports include 'loss', 'failure', 'default', 'termination' and 'adverse'. They then examine how such word lists are linked to company-level factors such as stock trading volume, unexpected earnings and fraud.

For the sample, PDF versions of company annual reports are hand collected from the Connect 4 website and converted to text files. The LM dictionary is applied to these text files to create the sample. Common steps in the natural language processing literature are taken to clean the raw dataset before analysis: numbers, punctuation marks, white spaces and common stop words are removed from each article. All words are then reduced to their respective 'stem', which is the part of a word that is common to all of its inflections (for example, 'performs', 'performing', and 'performed' are reduced to 'perform').

The word clouds in Figure 3 indicate that the most common positive words in Australian corporate disclosures are terms such as 'benefit', 'good' and 'success'. The most common negative words include terms such as 'loss', 'defer' and 'impair'. These word clouds do not appear to have changed much over time, as shown by a comparison of the 2005 and 2020 clouds. 
Figure 3: Sentiment Word Clouds

Positive sentiment

2005

progress

good

better

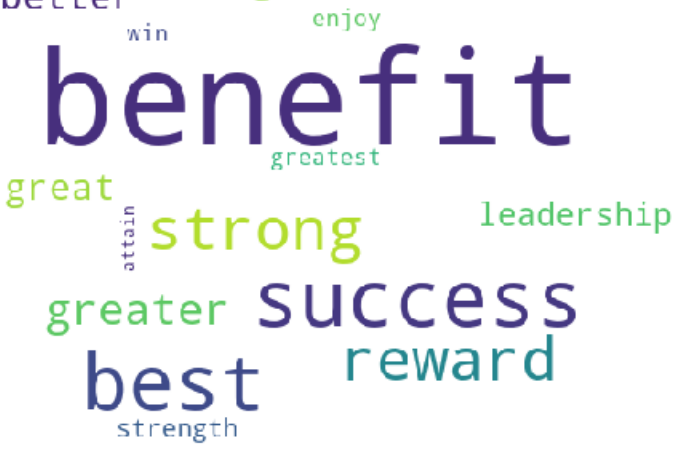

2020

best strong good leadership

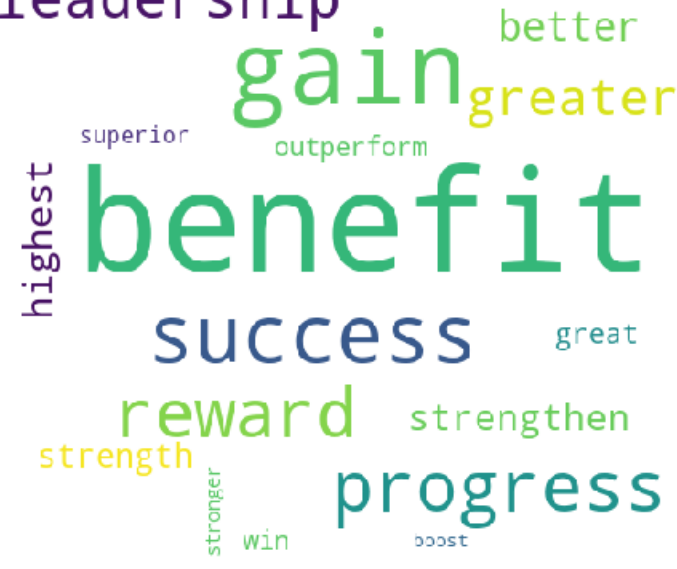

Negative sentiment

2005

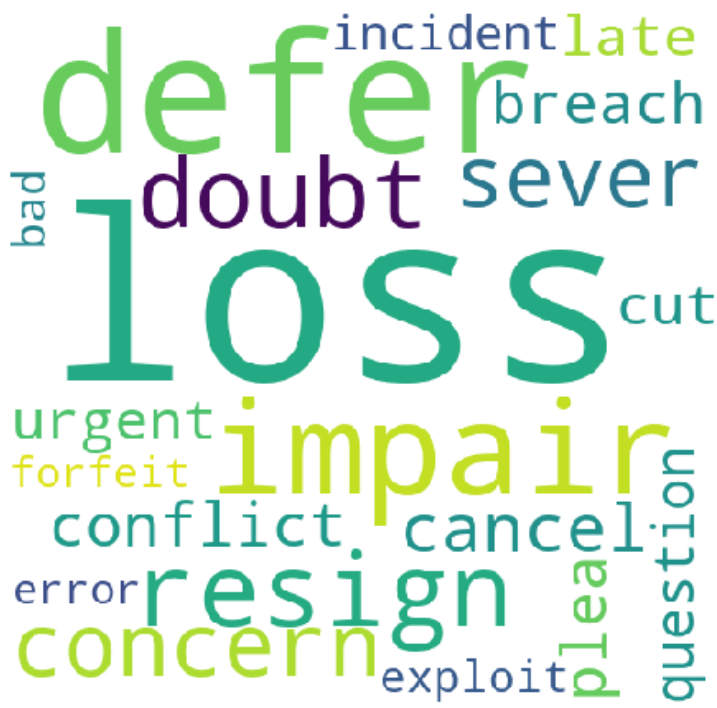

2020

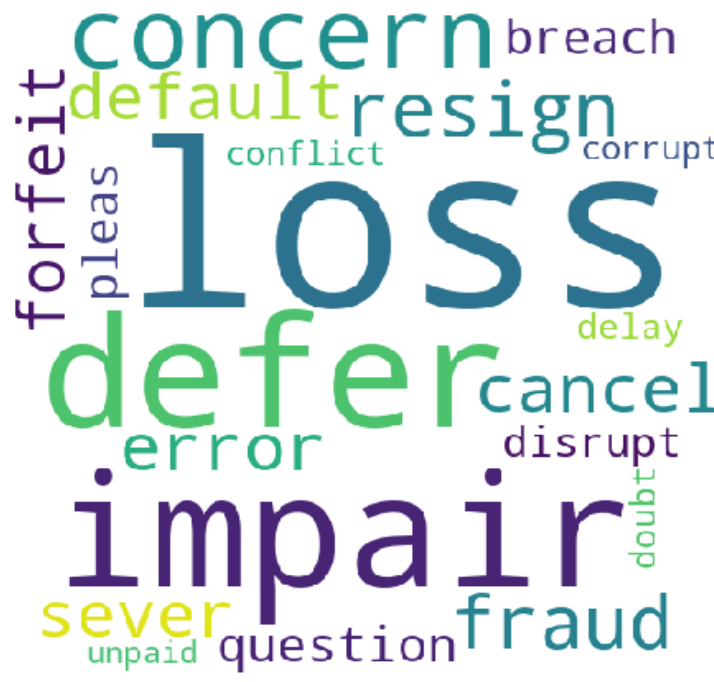

Note: $\quad$ The size of each word reflects its relative frequency

Sources: Author's calculations; Connect 4

However, the word clouds mask some apparent changes in the underlying language used in corporate disclosures. For instance, the net balance of positive words shows a clear downward trend over time based on the raw (unadjusted) data (top panel of Figure 4). This is caused by companies increasingly using words with a negative connotation (bottom panel of Figure 4). This may be due to a gradual shift in corporate disclosures towards 'investor-friendly' documents that are more transparent and include more discussion of risks and uncertainties to the outlook. 
Figure 4: Decomposition of Corporate Sentiment

Company level, financial year average

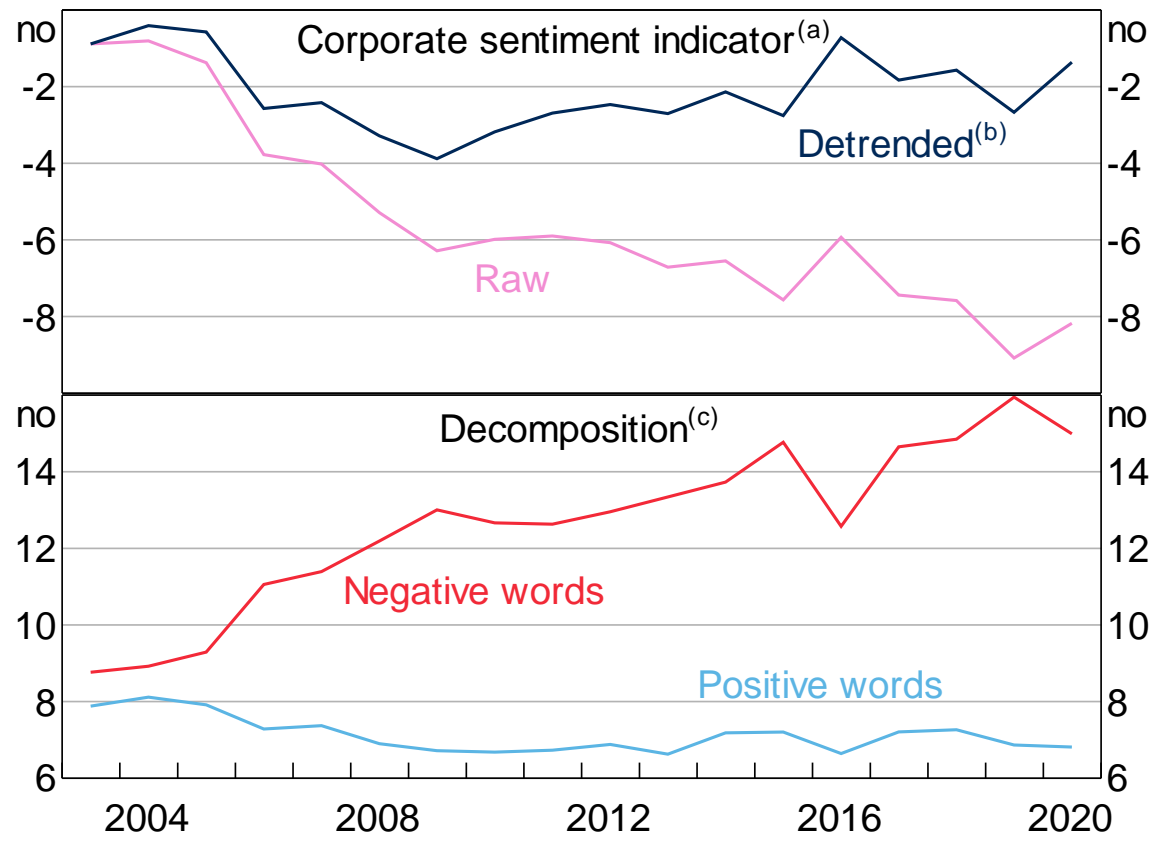

Notes: (a) Net balance of positive and negative words per 10,000 words

(b) Residuals from OLS regression of corporate sentiment on company dummies and a linear trend

(c) Based on unadjusted sentiment data

Sources: Author's calculations; Connect 4

If the increasing propensity to use negative language is due to a shift towards more risk-based reporting, rather than growing concerns about the outlook, then this will make it more difficult to identify the true effect of corporate sentiment on investment. I adjust for the apparent trend by estimating an OLS regression of the sentiment indicator on a company fixed effect and a linear trend, and take the residuals. These residual estimates are referred to as the 'adjusted' corporate sentiment indicator, and will be used for the remainder of the analysis in the paper. However, the key results in the paper hold even when using the unadjusted measure of sentiment. ${ }^{4}$

\subsection{Company-level investment and fundamentals}

Corporate investment is measured as the log change in the net capital stock $\left(\frac{\Delta K}{K}\right)$ as reported on a company's balance sheet, which is equivalent to the net investment rate $\left(\frac{I}{K}-\delta\right)$ :

$$
\frac{\Delta K}{K}=\frac{I}{K}-\delta
$$

4 Note that the net balance measure is normalised by the number of words per company report, and the trend over time in the net balance is not due to a decrease in the length of corporate disclosures (in fact, there has been an increase in average word count over time). The fact that the LM dictionary includes more negative words than positive words can explain why companies use more negative terms on average. However, the relative length of the word lists should be less of an issue for changes over time in sentiment, which is the main focus of the analysis in this paper. 
Here, the capital stock captures tangible assets such as property, plant \& equipment and is measured on a net basis by deducting accumulated depreciation from the gross capital stock. I choose to use the capital stock measure because it is generally more commonly reported in Australian company reports than the gross capital expenditure measure. (The key results hold though using the gross capital spending measure.)

To proxy for corporate fundamentals I construct an estimate of Tobin's Q using company-level information on share prices and the number of outstanding shares. Tobin's $Q$ is measured as:

$$
Q=\frac{E+L-\operatorname{In} v}{A}
$$

where $Q$ is the ratio of total market value of equity ( $E$ ) plus the book value of liabilities $(L)$ less inventories ( $I n v$ ) divided by the book value of total assets $(A)$.

There is extensive evidence that Tobin's $Q$ is a poor guide to future corporate performance (e.g. Erickson and Whited 2000). So, in the empirical specification, I also consider a range of other firm-level indicators that could proxy for fundamentals, such as annual growth in sales (or turnover), the return on assets (measured as the ratio of earnings before interest and tax to total assets) and equity analysts' profit forecasts for the year ahead. I also explore the role of measurement error in Tobin's $Q$ in a robustness test.

\subsection{Publicly listed company sample}

The sentiment indicator requires information on corporate disclosures, which means that the analysis is restricted to Australian publicly listed companies. The sample is an unbalanced panel of listed companies, with much of the data sourced from Morningstar. Share prices and equity analyst forecasts are sourced from Refinitiv Eikon. Before estimation, outliers are removed based on the top and bottom 1 per cent of the distribution of each of the investment rate, the sentiment indicator, the uncertainty indicator and the $\mathrm{Q}$ ratio. The sample covers close to 2,000 companies per year between 2003 and 2020.

Publicly listed companies account for about 1 in 2,000 companies and are typically older and larger than the average (unlisted) company. However, it is hard to be definitive about whether this sample leads to biased estimates of the effect of sentiment on investment. The regression sample appears to be broadly representative of the universe of listed companies. I find that there are no statistically significant differences between firm-year observations that are in the regression sample and those that are not in the sample on most measures, including investment and sentiment. The only exception is that firms in the regression sample are a bit larger (based on the book value of assets) and have a slightly lower $\mathrm{Q}$ ratio than those that are not in the regression sample.

\subsection{Information sets of company managers and investors}

To empirically identify the effect of sentiment on investment it is important to consider what is in the information sets of the managers and investors at the time of the release of the company annual reports, which are used to measure sentiment. 
As an example, consider a hypothetical company that releases its annual report for the financial year 2019/20 in August 2020. This report includes balance sheet information on the book value of the capital stock at the start (1 July 2019) and end of the financial year (30 June 2020), and therefore the flow of investment during 2019/20. The managers and investors can observe the share price on a daily basis at any time during 2019/20.

To capture the determinants of company investment decisions, I conservatively assume the relevant measure of Tobin's Q is based on the market and book values of the capital stock at the start of the financial year (1 July 2019), as these values are definitely observed by the managers at the time of any investment decision. I therefore restrict investor knowledge of the company, as captured in Tobin's $Q$, to the start of the period.

The end-of-year financial report is typically released a couple of months after the relevant financial year. This means that the language used in the report could reflect the knowledge of managers about investment-relevant events that occurred during and even after the reported financial year. This gives an information advantage to company managers, which may mean that the sentiment indicator is not a pure measure of animal spirits but is also capturing 'insider' knowledge of events that are relevant to investment, but which are not observed by the market at the start of the period.

To address this, I also consider an alternative version of the model in which Tobin's $Q$ is measured at the end of June 2020 and sentiment is measured based on the language in the 2018/19 financial report. I report on these alternative estimates in a robustness test.

\subsection{Summary statistics}

Some summary statistics are shown in Table 1 . Investment is clearly skewed across the corporate population with the average company investing about 10 per cent of its capital stock each year, while the median company invests closer to 3.3 per cent, with a high standard deviation. The average company also has a relatively high $\mathrm{Q}$ ratio, which appears to be mostly due to high valuations for mining companies during the mining boom period. This is despite the fact that the average company makes losses, as shown by the negative return on assets. The average company uses 7.2 positive words, 13.3 negative words and 5.7 uncertain words for every 10,000 words in its annual reports.

Table 1: Company-level Statistics

Sample period: 2003 to 2020

\begin{tabular}{lrrrrr}
\hline & Mean & Median & $\begin{array}{r}\text { Standard } \\
\text { deviation }\end{array}$ & $\begin{array}{c}\text { 25th } \\
\text { percentile }\end{array}$ & $\begin{array}{c}\text { 75th } \\
\text { percentile }\end{array}$ \\
\hline Investment rate (\%) & 10.3 & 3.3 & 84.1 & -20.5 & 31.9 \\
Positive sentiment (per 10,000 words) & 7.2 & 7.0 & 1.9 & 6.0 & 8.2 \\
Negative sentiment (per 10,000 words) & 13.3 & 13.2 & 3.5 & 11.1 & 15.4 \\
Uncertainty (per 10,000 words) & 5.7 & 5.7 & 1.9 & 4.5 & 6.9 \\
Q ratio (times) & 2.2 & 1.4 & 2.3 & 0.9 & 2.5 \\
Return on assets (\%) & -15.3 & -3.7 & 87.7 & -23.3 & 12.9 \\
Sales growth (\%) & 10.0 & 7.2 & 110.2 & -21.5 & 38.6 \\
\hline Note: Sample statistics based on estimation sample for the baseline fixed effects regression & & \\
Sources: Author's calculations; Connect 4; Morningstar; Refinitiv Eikon \\
\hline
\end{tabular}




\section{The Effect of Corporate Sentiment Shocks}

\subsection{The distribution of sentiment and investment}

Before turning to the statistical analysis, it is helpful to look at the data underpinning the regression modelling. The key dependent variable is the net investment rate (or change in the net capital stock). The company-level data indicates a wide dispersion in investment outcomes across companies each year as shown by the difference between the 25th and 75th percentiles of the distribution (top panel of Figure 5). Across the company distribution there is an apparent shift down in the rate of investment around the time of the GFC, with a recovery from around 2015.

For the corporate sentiment indicator, there is also a wide distribution of outcomes at any point in time (middle panel of Figure 5). The sentiment indicator shows a clear cyclical pattern, with sentiment declining during the GFC. There is little evidence that corporate sentiment fell during 2019/20, perhaps because the COVID-19 pandemic only affected economic activity in the last quarter of that year. The $\mathrm{Q}$ ratio also displays clear cyclical fluctuations (bottom panel of Figure 5).

Figure 5: Distribution of Corporate Indicators

Company level

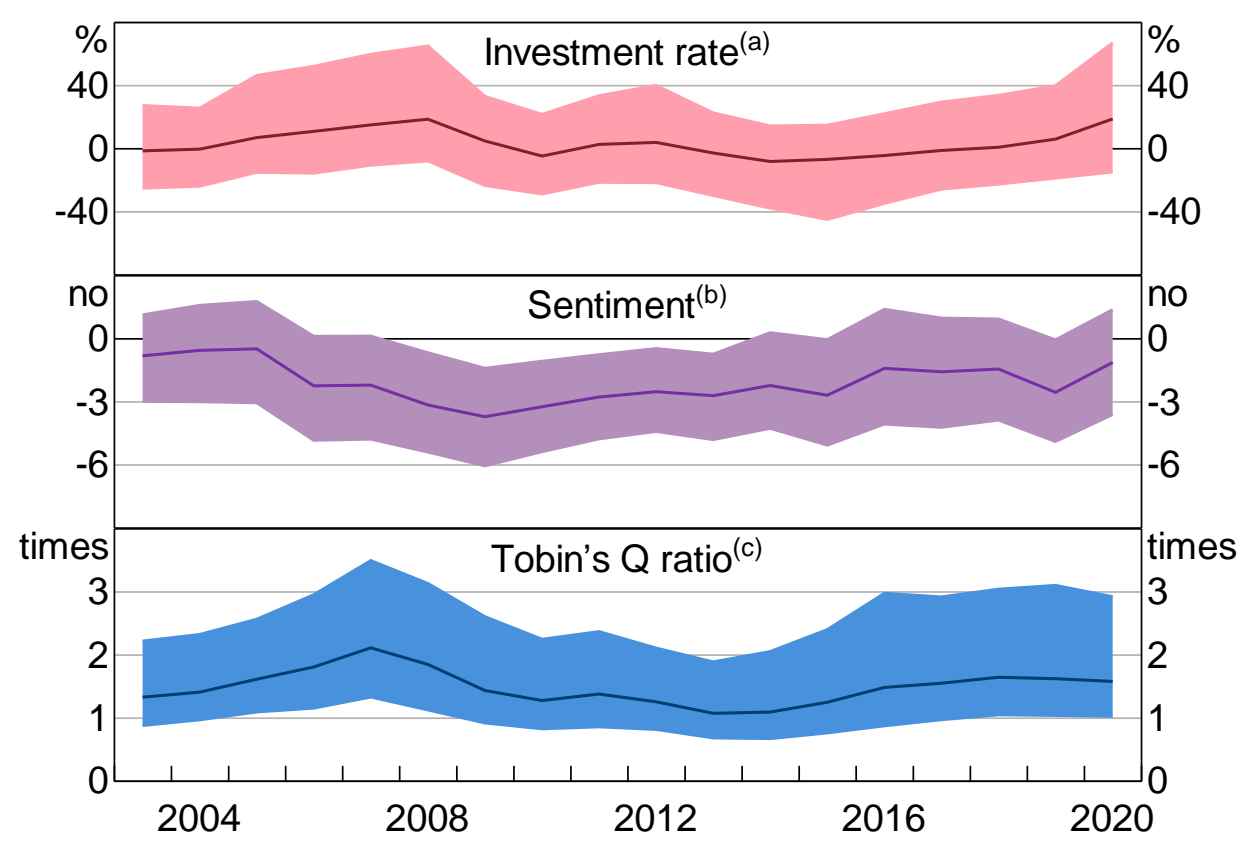

Notes: $\quad$ Median shown by the line while the shaded area shows the 25th to 75th percentiles

(a) Measured as annual change in net capital stock

(b) Measured as the net balance of positive and negative words per 100,000 words

(c) Measured as (market value of equity plus book value of liabilities less inventories) divided by book value of assets

Sources: Author's calculations; Connect 4; Morningstar; Refinitiv Eikon

We can also look at how corporate investment is distributed across measures of sentiment, uncertainty and fundamentals. To see this, binned scatterplots are constructed and the average investment rate is calculated for deciles of the distribution of the corporate sentiment indicator, the $\mathrm{Q}$ ratio and the corporate uncertainty indicator (Figure 6). Companies that report higher levels of sentiment also invest more on average (top panel). Companies with particularly low sentiment levels scale back investment significantly, as shown by the bottom decile. There is a similar positive 
correlation in the cross-section between the corporate investment rate and the Tobin's $\mathrm{Q}$ ratio (middle panel). Further, there is a strong negative correlation in the cross-section between the investment rate and uncertainty (bottom panel). Taken at face value, this is consistent with investment being a function of sentiment, fundamentals and uncertainty.

Figure 6: Corporate Investment Rate

By decile of relevant indicator

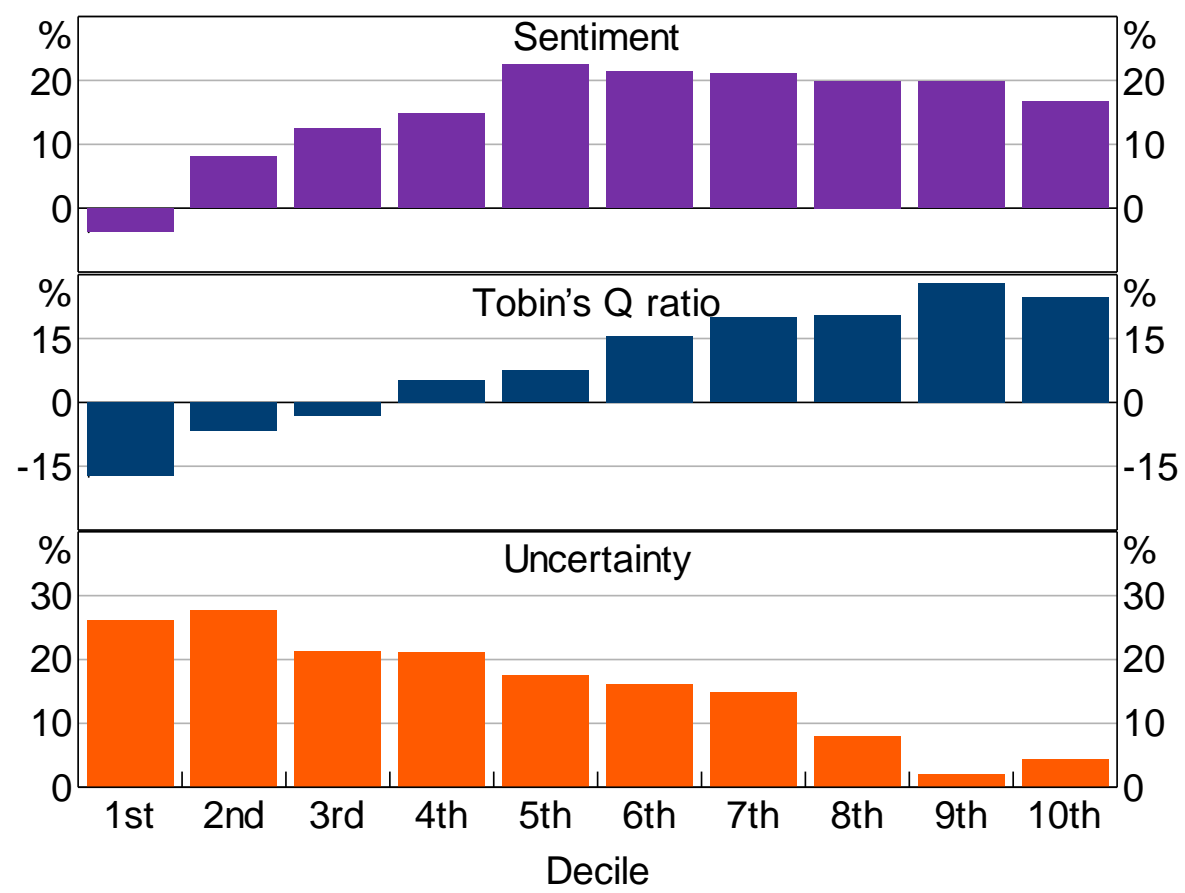

Sources: $\quad$ Author's calculations; Connect 4; Morningstar; Refinitiv Eikon

\subsection{The effect of sentiment on investment}

To explore the determinants of investment a standard Tobin's Q model is augmented with the indicators of corporate sentiment and uncertainty:

$$
\frac{\Delta K_{i t}}{K_{i t-1}}=\beta S_{i t}+\gamma Q_{i t}+\pi U_{i t}+\delta C O N T R O L S_{i t}+\theta_{i}+\lambda_{t}+\varepsilon_{i t}
$$

The dependent variable is the change in the net capital stock $\left(\frac{\Delta K_{i t}}{K_{i t-1}}\right)$, or the net investment rate, for company $i$ in year $t$. The key explanatory variable is corporate sentiment $\left(S_{i t}\right)$, measured as the ratio of net positive words to total words in each company's annual report, alongside the Tobin's $\mathrm{Q}$ ratio $\left(Q_{i t}\right)$. If sentiment matters to business investment, we would expect a positive correlation between corporate sentiment and the rate of investment. The model also includes controls for other factors that may be associated with investment, such as profitability, growth and size. Also considered is a regression in which firm-level uncertainty $\left(U_{i t}\right)$ is controlled for.

To identify the causal effect of sentiment on investment, there are at least two potential identification challenges. First, the level of manager sentiment may be correlated with adjustment cost shocks that are observed by the firm. For example, a factory may have to unexpectedly shut down for a 
period of time to replace the capital. This might have an adverse effect on the sentiment of the management team. In this case, we would have a positive correlation between sentiment and the error term and the estimated coefficient on sentiment will be biased upwards:

$$
\hat{\beta}=\beta+\frac{\operatorname{cov}\left(S_{i t}, \varepsilon_{i t}\right)}{\operatorname{var}\left(S_{i t}\right)}>\beta
$$

To partly address this, I consider alternative model specifications that test the sensitivity of investment to sentiment based on prior company reports (which should contain no knowledge of any adjustment cost shock).

The OLS estimates point to a significant positive correlation between sentiment and investment (Table 2). A one standard deviation (sd) increase in the share of net positive words (which is about 3.5 in 10,000 words) is associated with an increase in the rate of investment of about 6 percentage points (so the investment rate rises from about 10 per cent to 16 per cent at the sample mean). ${ }^{5}$ The correlation between sentiment and investment is unaffected by either the inclusion of Tobin's $\mathrm{Q}$ (comparing columns 1 and 2) or the inclusion of other proxies for fundamentals, such as profits and sales growth (comparing columns 1 and 3). Moreover, the result is driven mostly by the time series (within-company) variation in sentiment and investment - companies typically invest more when they use more net positive words, all other things being equal. This is shown by the stronger effect of sentiment when company fixed effects are included (comparing columns 2 and 3 ).

The $\mathrm{Q}$ ratio is also positively associated with investment. A 1 per cent increase in investment opportunities, as measured by $Q$, is associated with the rate of investment rising by 2 percentage points on average (a one standard deviation shock is associated with the investment rate being about 5 percentage points higher, all else equal). As expected, investment is also positively correlated with other indicators of fundamentals, such as sales growth and profitability.

Furthermore, adding a measure of uncertainty to the set of control variables (column 4) we find that uncertainty is negatively associated with investment, and the effect appears to be of a similar magnitude to that of sentiment. But controlling for firm-level uncertainty has a limited effect on the sensitivity of investment to sentiment. This suggests that they both have roles to play in explaining corporate investment behaviour.

5 This effect of sentiment on investment is estimated as $\hat{\beta} \times$ sd in sentiment $\times 100=0.018 \times 3.49 \times 100=6.3 \%$. 
Table 2: The Effect of Corporate Sentiment on Investment

Sample period: 2003 to 2020

\begin{tabular}{|c|c|c|c|c|}
\hline & $\begin{array}{l}\text { OLS with } \\
\text { no controls }\end{array}$ & $\begin{array}{l}\text { OLS with } \\
\text { controls }\end{array}$ & $\begin{array}{l}\text { Fixed effects with } \\
\text { controls }\end{array}$ & $\begin{array}{l}\text { Fixed effects with } \\
\text { controls and } \\
\text { uncertainty indicator }\end{array}$ \\
\hline Sentiment & $\begin{array}{l}0.02^{* * *} \\
(4.05)\end{array}$ & $\begin{array}{l}0.02^{* * *} \\
(3.75)\end{array}$ & $\begin{array}{l}0.03 * * * \\
(5.22)\end{array}$ & $\begin{array}{l}0.03^{* * *} \\
(4.50)\end{array}$ \\
\hline Tobin's Q & & $\begin{array}{l}0.02^{* * *} \\
(4.98)\end{array}$ & $\begin{array}{l}0.02^{* * *} \\
(3.03)\end{array}$ & $\begin{array}{l}0.02^{* * *} \\
(3.06)\end{array}$ \\
\hline Uncertainty & & & & $\begin{array}{l}-0.04 * * \\
(-4.02)\end{array}$ \\
\hline Return on assets & & & $\begin{array}{l}0.11^{* * *} \\
(4.63)\end{array}$ & $\begin{array}{l}0.11^{* * *} \\
(4.66)\end{array}$ \\
\hline Sales growth & & & $\begin{array}{l}0.16^{* * *} \\
(8.53)\end{array}$ & $\begin{array}{l}0.16^{* * *} \\
(8.47)\end{array}$ \\
\hline Lagged sales level & & & $\begin{array}{l}0.16^{* * *} \\
(7.84)\end{array}$ & $\begin{array}{l}0.16 * * * \\
(7.87)\end{array}$ \\
\hline Lagged capital stock level & & & $\begin{array}{l}-0.25^{* * *} \\
(-13.44)\end{array}$ & $\begin{array}{l}-0.25 * * * \\
(-13.50)\end{array}$ \\
\hline Company fixed effects & $\mathrm{N}$ & $\mathrm{N}$ & $\mathrm{Y}$ & $Y$ \\
\hline Year fixed effects & $\mathrm{N}$ & $\mathrm{N}$ & Y & Y \\
\hline R squared & $0.5 \%$ & $1.6 \%$ & $32.9 \%$ & $33.1 \%$ \\
\hline Companies & 2,050 & 1,210 & 999 & 999 \\
\hline Observations & 11,733 & 7,440 & 7,215 & 7,215 \\
\hline $\begin{array}{ll}\text { Notes: } & *, * * \text { and } * * * \text { der } \\
& \text { standard errors ar } \\
& \text { are omitted }\end{array}$ & $\begin{array}{l}\text { atistical significa } \\
\text { way clustered b }\end{array}$ & $\begin{array}{l}\text { e } 10,5 \text { and } 1 \\
\text { d year; coeffi }\end{array}$ & $\begin{array}{l}\text { th levels, respectively, } \\
\text { imates for constant, fir }\end{array}$ & $\begin{array}{l}t \text {-statistics in parentheses; } \\
\text { ummies and year dummies }\end{array}$ \\
\hline
\end{tabular}

\subsection{The dynamics of corporate sentiment, uncertainty and investment}

The dynamics of investment in response to shocks to sentiment and other variables in the model may tell us more about the mechanism through which changes in sentiment are associated with changes in investment. For instance, if sentiment is a proxy for news about future company performance then we may expect the effect of a sentiment shock on investment to be relatively persistent (Barsky and Sims 2012). If sentiment is instead capturing noise or animal spirits, then the effect may be expected to be temporary, or at least more temporary than a similar shock to a fundamental proxy such as Tobin's Q.

To examine the dynamics of the relationship between sentiment and investment I estimate a series of impulse response functions using the local projections (LP) method of Jordà (2005). Specifically, for each forecast horizon $(h)$ I run a regression of the annual investment rate on standardised 'sentiment shocks' as well as a series of lagged controls:

$$
\left(\frac{I}{K}\right)_{i, t+h}-\left(\frac{I}{K}\right)_{i, t}=\alpha_{i, h}+\beta_{h} s_{i, t}+\gamma_{h} Q_{i, t}+\pi_{h} U_{i, t}+\mu_{h} \text { CONTROLS }_{i, t-1}+\varepsilon_{i, t+h}
$$


Here, a sentiment shock is measured by a one standard deviation change in the sentiment indicator conditional on a set of controls that includes Tobin's $Q$, uncertainty, sales growth, the lagged level of the net capital stock and the lagged level of sales. Similarly, a Q shock is measured by a one standard deviation change in the Tobin's $Q$ ratio conditional on sentiment and the same set of controls. Further, an uncertainty shock is measured by a one standard deviation change in the uncertainty indicator conditional on sentiment, $Q$ ratio and the controls. The sentiment, $Q$ ratio and uncertainty measures are standardised to $z$-scores by subtracting the firm-level mean and dividing by the firm-level standard deviation.

The horizon-zero version of the LP model is almost identical to the baseline regression presented in Section 4.2 (with the full set of control variables). The only difference is that the local projections include the one-year lag of each of the standardised indicators of sentiment, uncertainty and Tobin's Q. For example, the sentiment indicator is serially correlated, so including lags is important to be able to interpret the coefficients as the response to sentiment 'shocks'.

The impulse response of the investment rate to the sentiment shock is traced out by the estimates of the $\beta \mathrm{s}$. The impulse response of the investment rate to the $Q$ and uncertainty shocks are similarly traced out by the estimates of the $\gamma \mathrm{s}$ and the $\pi \mathrm{s}$.

The estimated impulse response suggests that a standardised sentiment shock has a persistent positive correlation with investment, with the rate of investment being 10 percentage points higher after about three years before gradually declining (Figure 7). This would imply the average investment rate rises from 10 per cent to 20 per cent at the peak. The size of the investment response to a one standard deviation Tobin's $Q$ shock is of a similar magnitude but more persistent than a sentiment shock. The (negative) effect on investment of a standardised uncertainty shock is smaller in size to the sentiment shock and more temporary. Overall, all three shocks appear to matter to investment at the company level.

The fact that the sentiment shock has an effect that lasts beyond a couple of years suggests that the sentiment indicator is at least partly capturing news about a company's future productivity. Alternatively, it may indicate that an animal spirits shock has a self-fulfilling nature in which fundamentals adjust to the initial demand shock to render the change in sentiment rational ex post. Moreover, the effect of a shock to sentiment appears to be less persistent than that of a similar shock to Tobin's Q. Overall, this empirical exercise provides mixed evidence on whether the sentiment indicator is capturing news or noise. 


\section{Figure 7: Response of Corporate Investment Rate to Various Shocks}

Shock: one standard deviation increase in each indicator

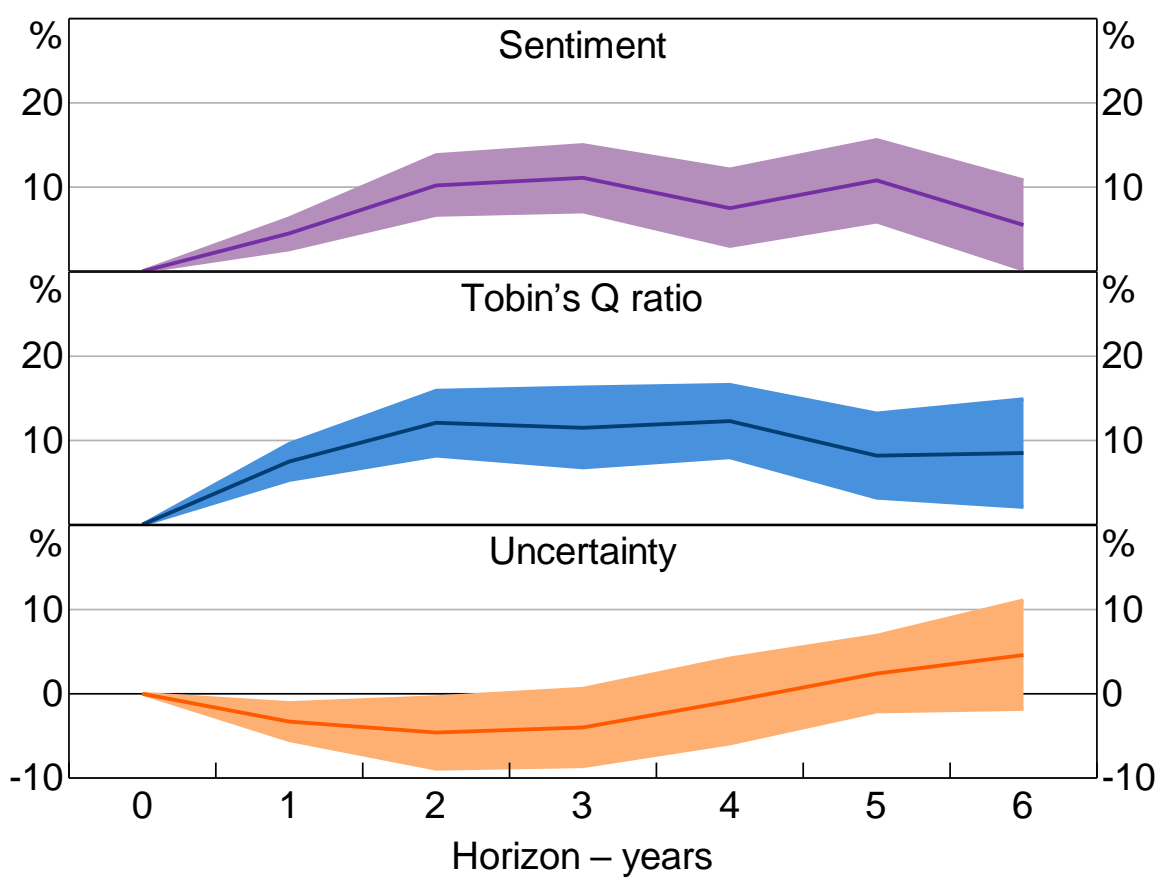

Notes: $\quad$ Shaded areas show 95 per cent confidence interval; standard errors are two-way clustered by company and year

Sources: Author's calculations; Connect 4; Morningstar; Refinitiv Eikon

\section{Robustness Tests and Extensions}

Several robustness tests and extensions are outlined below. ${ }^{6}$ These tests are generally designed to inspect the mechanism(s) behind the link between sentiment and investment at the company level.

\subsection{Why does corporate sentiment matter to investment?}

\subsubsection{Private knowledge of company managers}

I first explore whether the positive association between sentiment and investment is due to company managers being better informed than investors about the fundamentals of the company. If this 'private knowledge hypothesis' is true, we should expect that the correlation between sentiment and investment is stronger at companies that are more difficult for investors to value. To test this, indicators are constructed for whether a firm is more difficult to value ex ante based on three metrics: 1) size, 2) age and 3) share turnover (the total number of shares traded during the year divided by the average number of shares outstanding). Separate dummy variables $\left(D_{i}\right)$ are constructed to indicate whether the company is small (with total assets valued at less than $\$ 10$ million), young (less than four years of age) and/or low in turnover (in the bottom quartile of the stock turnover distribution). The dummy variable for hard-to-value companies is interacted with each of the

6 The key results are similar if investment is measured as the ratio of capital spending to revenue rather than the change in the net capital stock. I also find that the effect of sentiment on investment varies somewhat by industry, with the effect of sentiment being stronger in the mining sector. The effect of sentiment on investment is not any weaker or stronger during economic downturns such as the GFC and the COVID-19 pandemic. 
indicators for sentiment, uncertainty and Tobin's Q in separate regressions that augment the baseline model:

$$
\frac{\Delta K_{i t}}{K_{i t-1}}=\beta_{1} S_{i t}+\beta_{2} S_{i t} * D_{i}+\gamma_{1} Q_{i t}+\gamma_{2} Q_{i t} * D_{i}+\pi_{1} U_{i t}+\pi_{2} U_{i t} * D_{i}+\delta C O N T R O L S_{i t}+\theta_{i}+\lambda_{t}+\varepsilon_{i t}
$$

If the private knowledge hypothesis is true, there should be a stronger positive correlation between sentiment and investment for these hard-to-value companies $\left(\beta_{2}>0\right)$.

Based on these indicators there is little evidence that the positive effect of sentiment on investment is stronger for hard-to-value companies (Table 3). The sentiment effect is slightly stronger at smaller companies, but the effect is not statistically significant. The age effects point in the opposite direction, with the sensitivity of investment to sentiment being weaker at young companies, though also not statistically significant. These tests provide limited support for the idea that the sensitivity of investment to sentiment is explained by the private knowledge of corporate managers. ${ }^{7}$

Table 3: The Heterogeneous Effect of Corporate Sentiment on Investment

Sample period: 2003 to 2020

\begin{tabular}{lccc}
\hline & Based on size & Based on age & Based on share turnover \\
\hline Sentiment & $0.03^{* *}$ & $0.03^{* * *}$ & $0.03^{* * *}$ \\
& $(4.89)$ & $(4.79)$ & $(4.52)$ \\
Sentiment $\times$ Hard-to-value & 0.01 & -0.02 & -0.00 \\
indicator & $(0.54)$ & $(-1.57)$ & $(-0.48)$ \\
Tobin's Q & $0.04 * * *$ & $0.02 * * *$ & $0.02 * * *$ \\
& $(3.57)$ & $(2.87)$ & $(3.25)$ \\
Tobin's Q $\times$ Hard-to-value & $-0.04 * * *$ & $0.04 * * *$ & -0.01 \\
indicator & $(-2.85)$ & $(2.22)$ & $(-0.57)$ \\
Uncertainty & -0.01 & $-0.04 * * *$ & $-0.03 * * *$ \\
& $(-1.18)$ & $(-4.26)$ & $(-3.79)$ \\
Uncertainty $\times$ Hard-to-value & $-0.06 * * *$ & 0.02 & -0.01 \\
indicator & $(-3.45)$ & $(0.98)$ & $(-0.50)$ \\
\hline Company fixed effects & $Y$ & $Y$ & $Y$ \\
Year fixed effects & $Y$ & $Y$ & $Y$ \\
R squared & $34.2 \%$ & $33.4 \%$ & $33.2 \%$ \\
Companies & 998 & 998 & 998 \\
Observations & 7,208 & 7,208 & 7,208 \\
\hline
\end{tabular}

Notes: $\quad *, * *$ and $* * *$ denote statistical significance at the 10,5 and 1 per cent levels, respectively, with $t$-statistics in parentheses; standard errors are two-way clustered by firm and year; coefficient estimates for the control variables (return on assets, sales growth, lagged sales and lagged capital stock), constant, firm dummies and year dummies are omitted

Sources: $\quad$ Author's calculations; Connect 4; Morningstar; Refinitiv Eikon

7 It might be the case that firm size and age proxy for financial constraints, as well as information frictions, and that the investment behaviour of such financially constrained firms may be less sensitive to sentiment shocks simply because the firms are unable to respond to such changes in expected activity. Some of the control variables will capture financial constraints, such as the return on assets and sales growth, but they are likely to be imperfect controls. 
An alternative identification strategy to test whether the sensitivity of investment to sentiment is due to private knowledge is to explore the dynamics of the relationship between sentiment and company value, rather than investment. If the sentiment indicator is a proxy for managerial private knowledge about company fundamentals, then changes in sentiment should predict future company profits. I test this idea by estimating the same local projections as before, but the dependent variable is changed from investment to company profits (as measured by the return on assets). I then explore how profits react to (past) changes in sentiment and Tobin's Q.

The LP estimates reveal that the return on assets increases by about 4 percentage points in the year following a one standard deviation increase in the sentiment indicator, but the effect fades quickly (Figure 8). The effect of a change in Tobin's Q is slightly weaker (at about 2 percentage points at the peak) but more persistent, lasting a few years. Overall, these results suggest that the sentiment indicator may provide some short-term news about the company, but given the effect is very transitory, the sensitivity of investment to sentiment does not appear to be fully explained by managers having private information about company prospects.

Figure 8: Response of Return on Assets to Various Shocks

Shock: one standard deviation increase in each indicator

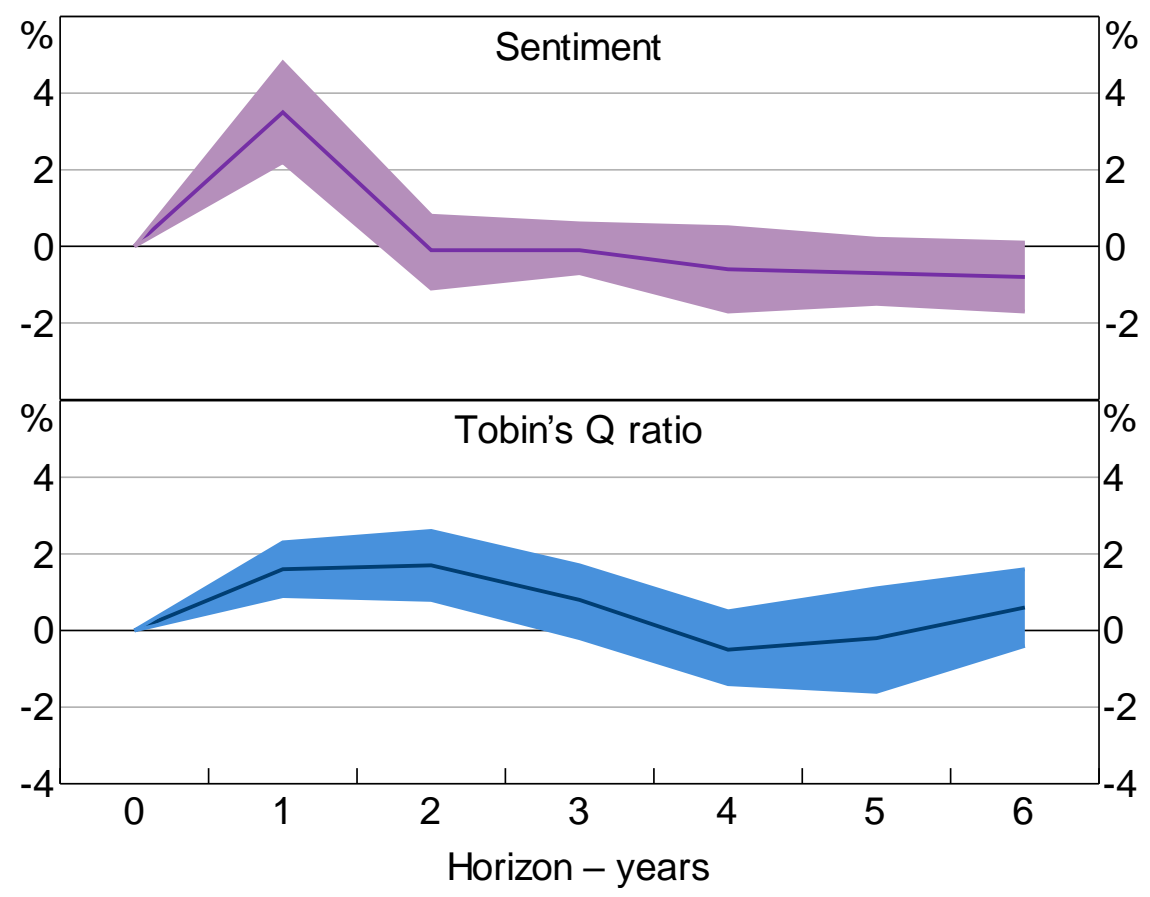

Notes: $\quad$ Shaded areas show 95 per cent confidence interval; standard errors are two-way clustered by company and year

Sources: Author's calculations; Connect 4; Morningstar; Refinitiv Eikon

\subsubsection{Positive versus negative sentiment}

To further unpack the mechanism, the sentiment indicator can be decomposed into positive and negative sentiment, so that we can explore which matters more to investment. For this, the net balance measure is split into two indicators - the share of positive words ('positive sentiment') and the share of negative words ('negative sentiment') that are expressed in corporate disclosures. The model is then re-estimated using these two separate indicators simultaneously. 
The results indicate that both positive and negative sentiment matter to investment, though the effect is stronger for 'negativity' expressed in corporate disclosures (Table 4). This may be because negative words provide a stronger indicator of how a company is faring. Companies presumably avoid using negative words if they can, so when they do use them it is more informative than the use of positive words. This may indicate the sensitivity of investment to sentiment is at least partly due to managers having some private knowledge about the company's future (bad) prospects. However, it could also be that the text analysis is better able to capture negative language than positive language, because positive language may be more nuanced. This would suggest that there is more measurement error in the positive sentiment indicator.

\begin{tabular}{|c|c|c|}
\hline \multicolumn{3}{|c|}{$\begin{array}{l}\text { Table 4: The Effect of Corporate Sentiment on Investment } \\
\text { Sample period: } 2003 \text { to } 2020\end{array}$} \\
\hline & OLS with no controls & Fixed effects with controls \\
\hline \multirow[t]{2}{*}{ Positive sentiment } & $-0.01 *$ & $0.02 *$ \\
\hline & $(-3.24)$ & $(2.18)$ \\
\hline \multirow[t]{2}{*}{ Negative sentiment } & $-0.03 * * *$ & $-0.03 * * *$ \\
\hline & $(-10.89)$ & $(-6.68)$ \\
\hline \multirow[t]{2}{*}{ Tobin's Q } & & 0.01 \\
\hline & & $(0.88)$ \\
\hline \multirow[t]{2}{*}{ Uncertainty } & & $-0.03 * * *$ \\
\hline & & $(-2.72)$ \\
\hline \multirow[t]{2}{*}{ Return on assets } & & $0.09 * * *$ \\
\hline & & $(3.26)$ \\
\hline \multirow[t]{2}{*}{ Sales growth } & & $0.17^{* * *}$ \\
\hline & & $(9.02)$ \\
\hline \multirow[t]{2}{*}{ Lagged sales level } & & $0.16 * * *$ \\
\hline & & $(8.34)$ \\
\hline \multirow[t]{2}{*}{ Lagged capital stock level } & & $-0.26 * * *$ \\
\hline & & $(-17.46)$ \\
\hline Company fixed effects & $\mathrm{N}$ & Y \\
\hline Year fixed effects & $\mathrm{N}$ & $\mathrm{Y}$ \\
\hline R squared & $1.0 \%$ & $32.2 \%$ \\
\hline Companies & 1,964 & 964 \\
\hline Observations & 11,200 & 6,931 \\
\hline \multirow{2}{*}{$\begin{array}{l}\text { are omitted } \\
\text { Author's calculati }\end{array}$} & $\begin{array}{l}\text { nificance at the } 10,5 \text { and } \\
\text { red by firm and year; coef }\end{array}$ & $\begin{array}{l}\text { ectively, with } t \text {-statistics in parentheses; } \\
\text { nstant, firm dummies and year dummies }\end{array}$ \\
\hline & lorningstar; Refinitiv Eikon & \\
\hline
\end{tabular}

\subsection{The measurement of corporate fundamentals}

\subsubsection{Measurement error in corporate fundamentals and sentiment}

A key challenge to establishing a causal link between sentiment and investment is potential measurement error in the explanatory variables. Even if the sentiment indicator is measured perfectly, the estimated correlation between sentiment and investment will be affected by poor measurement of other explanatory variables, such as Tobin's Q. It has long been recognised that 
Tobin's Q can be a poor proxy for unobserved investment opportunities, and various fixes have been proposed (Erickson and Whited 2012).

In a bivariate regression of investment on a single explanatory variable that is measured with error, the estimated coefficient will be biased towards zero due to 'attenuation bias'. But, in a multivariate setting, it is more complicated and difficult to sign the effect of the bias on any one explanatory variable due to mismeasurement of other explanatory variables (Pishcke 2007).

But, in some special cases, it is possible to sign the estimation bias. For instance, assume that, in the absence of error, sentiment and marginal $q$ are positively correlated, say, because an increase in productivity increases the value of the company and makes company managers more optimistic about the future. In this case, classical error in measuring $q$ will cause investment to be too sensitive to changes in sentiment but not sensitive enough to changes in Tobin's Q (Pishcke 2007).

To identify the role of measurement error, I follow an 'error-in-variables' approach and estimate the effect of sentiment on investment using the Erickson and Whited (2012) (EW) estimator. This is a minimum distance technique that relies on higher-order moments to strip out the effect of measurement error. This technique assumes that marginal $\mathrm{q}$ and sentiment follow non-normal distributions, which seems reasonable in practice given how skewed the observable data are.

The benchmark OLS regression estimates are shown in column 1, Table 5 . The results of using the EW estimator are shown separately for the case where marginal $q$ is assumed to be the only variable measured with error (column 2) and also where both marginal q and sentiment are assumed to be measured with error (column 3).

Table 5: Investment, Sentiment, Tobin's Q and Measurement Error

Sample period: 2003 to 2020

\begin{tabular}{lccc}
\hline & Baseline & Mismeasured Tobin's Q & Mismeasured Tobin's Q and sentiment \\
\hline Sentiment & $0.01^{* * *}$ & $0.02^{* * *}$ & 0.23 \\
& $(3.80)$ & $(4.40)$ & $(1.16)$ \\
Tobin's Q & $0.02^{* * *}$ & 0.02 & 0.03 \\
& $(4.04)$ & $(1.09)$ & $(1.19)$ \\
\hline Company fixed effects & $\mathrm{N}$ & $\mathrm{N}$ & $\mathrm{N}$ \\
Year fixed effects & $\mathrm{N}$ & $\mathrm{N}$ & $\mathrm{N}$ \\
R squared & $8.1 \%$ & $17.3 \%$ & $21.2 \%$ \\
Companies & 999 & 999 & 999 \\
Observations & 7,215 & 7,215 & 7,215 \\
\hline
\end{tabular}

Notes: $\quad *, * *$ and $* * *$ denote statistical significance at the 10,5 and 1 per cent levels, respectively, with $t$-statistics in parentheses; coefficient estimates for some of the control variables (return on assets, sales growth, lagged sales and lagged capital stock) and constant are omitted

Sources: Author's calculations; Connect4; Morningstar; Refinitiv Eikon

Under the assumption that Tobin's $Q$ is the only variable that is mismeasured, the sensitivity of investment to sentiment is stronger, and the effect of Tobin's $Q$ is basically unchanged (comparing columns 1 and 2). Under the assumption that both Tobin's $Q$ and sentiment are poorly measured, the sensitivity to sentiment becomes nearly ten times stronger, albeit not statistically significant (comparing columns 2 and 3). Overall, these results suggest that measurement error could be an 
issue, and that the effects of sentiment and Tobin's Q would be even stronger in the absence of such measurement issues. However, the results appear to be sensitive to model specification (including the order of moments to use in estimation).

\subsubsection{Alternative measures of corporate fundamentals}

We can also gauge the importance of sentiment and uncertainty for investment based on alternative measures of corporate fundamentals, such as company-specific expected profits. For this exercise, the Tobin's Q measure of fundamentals is replaced with equity analyst forecasts for earnings per share in the year ahead, and the baseline regression is re-estimated.

As discussed earlier, the timing of corporate disclosures may also give an information advantage to managers over the market in that they know more about the fundamentals at the time of writing the annual report. To address this, I consider an alternative version of the baseline model in which the sentiment indicator is lagged by one year and Tobin's $Q$ is measured based on the share price and number of outstanding shares at the end of the financial year (after the release of the relevant financial report). So, for a hypothetical company that reports investment in 2019/20, sentiment is measured in 2018/19 and Tobin's Q is measured at the end of June 2020.

The effect of sentiment on investment is unchanged, measured both in terms of economic magnitude and statistical significance, despite the inclusion of the expected profit indicator in column 1 (Table 6). Perhaps more remarkably, the sensitivity of investment to sentiment persists, despite the sample size being drastically reduced by the inclusion of this expected profit measure (as it is reported for only a select group of companies). The expected profit measure is also positively correlated with investment, as expected. Notably, the inclusion clearly affects the statistical significance of almost all the other variables in the model, but not sentiment and expected profits.

Similarly, investment remains sensitive to sentiment even when investors potentially have an information advantage over the managers because the market value of the company is measured at the end of the financial year (column 2 of Table 6). This is remarkable given that at least some investors are presumably using a similar text analysis approach to identify relevant information about future company prospects based on the language used in the annual disclosures. The net balance of positive and negative words can be easily measured by anyone with knowledge of machine learning techniques (or even straight dictionary-based analysis as used here) and access to the publicly available company reports. This should mean that any information gleaned from the language in the reports is already embedded in the share price and hence captured in Tobin's Q measured at the end of the financial year. And yet sentiment, as captured in corporate disclosures, still matters to investment. 
Table 6: Alternative Measures of Corporate Fundamentals

Sample period: 2003 to 2020

\begin{tabular}{|c|c|c|}
\hline & $\begin{array}{c}\text { Expected profits } \\
\text { (based on equity analyst forecasts) }\end{array}$ & $\begin{array}{l}\text { Lagged sentiment and end-period } \\
\text { Tobin's Q }\end{array}$ \\
\hline \multirow[t]{2}{*}{ Sentiment } & $0.02 * *$ & $0.03 * * *$ \\
\hline & $(4.46)$ & $(5.36)$ \\
\hline \multirow[t]{2}{*}{ Expected profits } & $0.04 *$ & \\
\hline & $(1.77)$ & \\
\hline \multirow[t]{2}{*}{ Tobin's Q (end period) } & & $0.02 *$ \\
\hline & & $(2.03)$ \\
\hline \multirow[t]{2}{*}{ Uncertainty } & -0.01 & $-0.04 * * *$ \\
\hline & $(-0.84)$ & $(-3.54)$ \\
\hline \multirow[t]{2}{*}{ Return on assets } & -0.03 & $0.14 * * *$ \\
\hline & $(-0.11)$ & $(4.96)$ \\
\hline \multirow[t]{2}{*}{ Sales growth } & 0.12 & $0.13^{* * *}$ \\
\hline & $(1.58)$ & $(6.56)$ \\
\hline \multirow[t]{2}{*}{ Lagged sales level } & 0.03 & $0.13^{* * *}$ \\
\hline & $(0.56)$ & $(5.78)$ \\
\hline \multirow[t]{2}{*}{ Lagged capital stock level } & $-0.27 * * *$ & $-0.25 * * *$ \\
\hline & $(-6.77)$ & $(-12.13)$ \\
\hline Company fixed effects & $Y$ & $\mathrm{Y}$ \\
\hline Year fixed effects & $\mathrm{Y}$ & $\mathrm{Y}$ \\
\hline R squared & $49.5 \%$ & $33.5 \%$ \\
\hline Companies & 274 & 805 \\
\hline Observations & 1,620 & 5,597 \\
\hline \multirow{2}{*}{$\begin{array}{ll} & \text { are omitted } \\
\text { Sources: } & \text { Author's calculati }\end{array}$} & $\begin{array}{l}\text { tical significance at the } 10,5 \text { and } 1 \text { per c } \\
\text { y clustered by firm and year; coefficient e }\end{array}$ & $\begin{array}{l}\text { respectively, with } t \text {-statistics in parentheses; } \\
\text { i constant, firm dummies and year dummies }\end{array}$ \\
\hline & ect 4; Morningstar; Refinitiv Eikon & \\
\hline
\end{tabular}

\subsection{Corporate sentiment and business surveys}

To further explore the mechanism linking sentiment to investment, I test whether the sentiment indicator is correlated with traditional survey-based measures of business sentiment. If there is a correlation with the survey-based measures, this should give us more comfort that corporate sentiment is capturing variation in beliefs amongst managers. For this exercise, I compare the (unweighted) average level of corporate sentiment in each financial year to an annualised measure of current business conditions as reported in the National Australia Bank's (NAB's) monthly business survey. Given the sentiment indicator is estimated on annual data, this exercise is restricted to a small sample size of 18 years (from 2002/03 to 2019/20).

To explore the correlations, I estimate an OLS regression of the average sentiment indicator on the NAB measure of business conditions, as well as controls for aggregate real GDP growth (to capture the business cycle) and a dummy for the GFC period which is equal to one if the financial year is $2008 / 09$ or $2009 / 10$ and is zero otherwise (to capture the drop in economic activity at this time). 
Despite the limited time series variation, the average level of sentiment is positively correlated with current business conditions as reported in the NAB survey (Table 7). This holds true even when controlling for aggregate GDP growth and the large swings in economic activity during the GFC. This provides further evidence that the sentiment indicator is capturing the beliefs of company managers, rather than other confounding factors associated with the business cycle.

\begin{tabular}{lcc}
\hline \multicolumn{3}{c}{ Table 7: Corporate Sentiment and Business Survey Conditions } \\
& Sample period: FY2003 to FY2020 \\
\hline & OLS with no controls & OLS with controls \\
\hline Business conditions & $0.05^{*}$ & $0.05^{* *}$ \\
& $(1.77)$ & $(3.32)$ \\
GDP growth & -19.89 \\
& & $(-0.90)$ \\
GFC dummy & $\mathrm{N}$ & $-1.32^{* * *}$ \\
& $\mathrm{~N}$ & $(-5.78)$ \\
\hline Company fixed effects & $17.3 \%$ & $\mathrm{~N}$ \\
Year fixed effects & 18 & $\mathrm{~N}$ \\
R squared & & $34.7 \%$ \\
Observations & $* * *$ and $* * *$ denote statistical significance at the 10,5 and 1 per cent levels, respectively, with $t$-statistics in parentheses; \\
\hline Notes: $\quad$ standard errors are robust; coefficient estimate for constant is omitted & \\
Sources: ABS; Author's calculations; Connect 4; Morningstar; NAB; Refinitiv Eikon & \\
\hline
\end{tabular}

\subsection{Explaining the post-GFC weakness in investment}

Next, I quantify how much of the post-GFC weakness in investment can be explained by changes in sentiment, uncertainty and other demand-side factors, such as profits and growth. For this empirical exercise, I consider a version of the baseline model:

$$
\frac{\Delta K_{i t}}{K_{i t-1}}=\beta S_{i t}+\gamma Q_{i t}+\pi U_{i t}+\delta C O N T R O L S_{i t}+\theta_{i}+\rho G F C_{t}+\varphi P O S T_{t}+\varepsilon_{i t}
$$

where the regression is as before, but, for simplicity, the year fixed effects have been replaced by two dummy variables - one for the GFC period $\left(G F C_{t}\right)$ which is assumed to cover the financial years from 2009 to 2010, and one for the post-GFC period ( $P O S T_{t}$ ) which is assumed to cover the financial years since 2011. These dummies capture the mean change in the investment rate from the period prior to the GFC.

I consider three versions of this regression. First, an unrestricted version that is estimated as above. Second, a slightly restricted version in which investment depends on sentiment and uncertainty but none of the other time-varying explanatory variables $(\gamma=\delta=0)$. Third, a fully restricted version in which there are no explanatory variables other than the company fixed effects and period dummies $(\beta=\gamma=\pi=\delta=0)$. 
The comparison of the unrestricted and fully restricted models indicates that the demand-side factors can explain about 80 per cent of the decline in corporate investment during the GFC (Figure 9). Demand-side factors also account for more than half the decline in investment in the period since the GFC. A comparison of the unrestricted and somewhat restricted models shows that these measures of sentiment and uncertainty explain about a quarter of the decline in investment during the GFC, but account for very little of the post-GFC weakness.

Figure 9: Corporate Investment Rate

Company-level average, relative to pre-GFC period

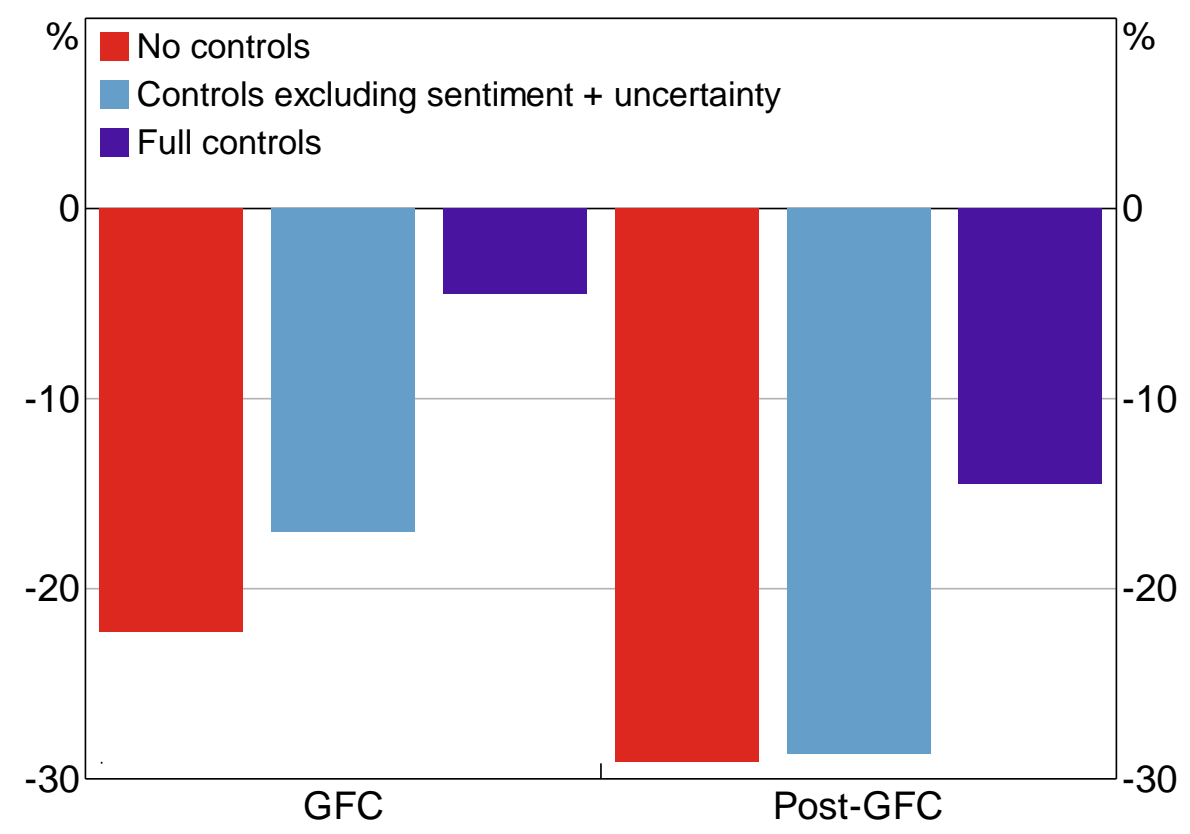

Sources: Author's calculations; Connect 4; Morningstar; Refinitiv Eikon

Overall, this empirical exercise suggests that weak demand-side factors are important for understanding the persistent weakness in corporate investment in the post-GFC period. And while low sentiment and heightened uncertainty were important contributing factors during the GFC, they have not obviously weighed on investment since that time.

\section{Policy Implications and Conclusions}

In this paper I develop new company-level indicators of corporate sentiment and uncertainty based on text analysis of corporate annual reports. I show that corporate sentiment has a statistically significant and robust positive association with company-level investment, even controlling for fundamentals and measures of uncertainty. Estimates from local projections suggest that the effect of sentiment on investment is less persistent than that of a fundamentals shock, as measured by Tobin's $Q$, which suggests that the link between sentiment and investment is at least partly reflective of animal spirits amongst corporate managers. The decline in sentiment and increase in uncertainty contributed to the weakness in investment during the GFC, but other demand-side factors such as sales growth are more important in explaining the persistent weakness in corporate investment observed since then. 
For policymakers, the results suggest that external communications may have real effects on the economy by influencing sentiment among corporate managers, even if fundamental factors are unaffected. Given the strong correlation between sentiment and investment at the company level, for policymakers, it may be worth investing more resources in behavioural macroeconomic models that allow for exogenous shocks to expectations amongst households and business decision-makers. Previous research has shown that, in such models, strict inflation targeting (as opposed to a more flexible approach based on average inflation over a longer period) can be suboptimal because it gives more scope for endogenous business cycle fluctuations that can destabilise inflation and output growth (De Grauwe 2011).

This paper focuses on the sentiment expressed in the text of corporate disclosures, which necessitates a focus on publicly listed companies, which are a very small and potentially biased sample of the business population. Therefore, there may be benefits to investing in panel surveys of the broader business population which survey expectations and uncertainties about future sales, employment and investment (similar to the Survey of Business Uncertainty in the United States, run by the Federal Reserve Bank of Atlanta).

The paper relies on a very simple text analysis approach to capture sentiment amongst companies. It may be worth exploring more sophisticated approaches that better capture the nuances of the language of economics and finance (Consoli, Barbaglia and Manzan 2020) or that capture the emotion as well as the tone of the language. 


\section{References}

Abel AB and OJ Blanchard (1986), 'The Present Value of Profits and Cyclical Movements in Investment', Econometrica, 54(2), pp 249-273.

Akerlof GA and RJ Shiller (2009), Animal Spirits: How Human Psychology Drives the Economy, and Why It Matters for Global Capitalism, Princeton University Press, Princeton.

Algaba A, D Ardia, K Bluteau, S Borms and K Boudt (2020), 'Econometrics Meets Sentiment: An Overview of Methodology and Applications', Journal of Economic Surveys, 34(3), pp 512-547.

Barsky RB and ER Sims (2012), 'Information, Animal Spirits, and the Meaning of Innovations in Consumer Confidence', The American Economic Review, 102(4), pp 1343-1377.

Beaudry P and F Portier (2014), 'News-Driven Business Cycles: Insights and Challenges', Journal of Economic Literature, 52(4), pp 993-1074.

Benhabib J and REA Farmer (1999), 'Indeterminancy and Sunspots in Macroeconomics', in JB Taylor and M Woodford (eds), Handbook of Macroeconomics: Volume 1A, Handbooks in Economics, 15, Elsevier B.V., Amsterdam, pp 387-448.

Benhabib J, P Wang and Y Wen (2015), 'Sentiments and Aggregate Demand Fluctuations', Econometrica, 83(2), pp 549-585.

Blanchard OJ, J-P L'Huillier and G Lorenzoni (2013), 'News, Noise, and Fluctuations: An Empirical Exploration', The American Economic Review, 103(7), pp 3045-3070.

Bloom N (2009), 'The Impact of Uncertainty Shocks', Econometrica, 77(3), pp 623-685.

Blundell R, S Bond, M Devereux and F Schiantarelli (1992), 'Investment and Tobin's $Q$ : Evidence from Company Panel Data', Journal of Econometrics, 51(1-2), pp 233-257.

Bond S and J Cummins (2001), 'Noisy Share Prices and the $Q$ Model of Investment', Institute for Fiscal Studies Working Paper WP01/22.

Chirinko RS (1993), 'Business Fixed Investment Spending: Modeling Strategies, Empirical Results, and Policy Implications', Journal of Economic Literature, 31(4), pp 1875-1911.

Consoli S, L Barbaglia and S Manzan (2021), 'Fine-Grained, Aspect-Based Sentiment Analysis on Economic and Financial Lexicon', Unpublished manuscript, 29 June. Available at <https://papers.ssrn.com/sol3/papers.cfm?abstract_id=3766194>.

De Grauwe P (2011), 'Animal Spirits and Monetary Policy', Economic Theory, 47(2-3), pp 423-457.

Dixit AK and RS Pindyck (1994), Investment under Uncertainty, Princeton University Press, Princeton.

Erickson T and TM Whited (2000), 'Measurement Error and the Relationship between Investment and $q$ ', Journal of Political Economy, 108(5), pp 1027-1057. 
Erickson T and TM Whited (2012), 'Treating Measurement Error in Tobin's $q$ ', The Review of Financial Studies, 25(4), pp 1286-1329.

Farmer REA (2012), 'Confidence, Crashes and Animal Spirits', The Economic Journal, 122(559), pp 155-172.

Gennaioli N, Y Ma and A Shleifer (2016), 'Expectations and Investment', in M Eichenbaum and JA Parker (eds), NBER Macroeconomics Annual 2015, 30, University of Chicago Press, Chicago, pp 379-431.

Gutiérrez G and T Philippon (2017), 'Investmentless Growth: An Empirical Investigation', Brookings Papers on Economic Activity, Fall, pp 89-169.

Hayashi F (1982), 'Tobin's Marginal $q$ and Average $q$ : A Neoclassical Interpretation', Econometrica, 50(1), pp 213-224.

Huang J and J Simon (2021), 'Central Bank Communication: One Size Does Not Fit All', RBA Research Discussion Paper No 2021-05.

Jiang F, J Lee, X Martin and G Zhou (2019), 'Manager Sentiment and Stock Returns', Journal of Financial Economics, 132(1), pp 126-149.

Jordà Ò (2005), 'Estimation and Inference of Impulse Responses by Local Projections', The American Economic Review, 95(1), pp 161-182.

Kearney C and S Liu (2014), 'Textual Sentiment in Finance: A Survey of Methods and Models', International Review of Financial Analysis, 33, pp 171-185.

Keynes JM (1936), The General Theory of Employment Interest and Money, Macmillan and Co., Limited, London.

Loughran T and B McDonald (2011), 'When Is a Liability Not a Liability? Textual Analysis, Dictionaries, and 10-Ks', The Journal of Finance, 66(1), pp 35-65.

Milani F (2017), 'Sentiment and the U.S. Business Cycle', Journal of Economic Dynamics \& Control, 82, pp 289-311.

Nowzohour L and L Stracca (2020), 'More Than a Feeling: Confidence, Uncertainty and Macroeconomic Fluctuations', Journal of Economic Surveys, 34(4), pp 691-726.

Pigou AC (1927), Industrial Fluctuations, MacMillan and Co., Limited, London.

Pischke S (2007), 'Lecture Notes on Measurement Error', Lecture Notes, London School of Economics and Political Science, Department of Economics. Available at <https://econ.Ise.ac.uk/staff/spischke/ec524/Merr_new.pdf>.

Roberts I and J Simon (2001), 'What do Sentiment Surveys Measure?', RBA Research Discussion Paper No 2001-09.

Zhou G (2018), 'Measuring Investor Sentiment', Annual Review of Financial Economics, 10, pp 239-259. 


\section{Copyright and Disclaimer Notice}

\section{BLADE Disclaimer}

The following Disclaimer Notice refers to data and graphs sourced from the Australian Bureau of Statistics' BLADE (Business Longitudinal Analysis Data Environment) database.

The results of this study are based, in part, on Australian Business Register (ABR) data supplied by the Registrar to the Australian Bureau of Statistics (ABS) under A New Tax System (Australian Business Number) Act 1999 and tax data supplied by the Australian Taxation Office (ATO) to the ABS under the Taxation Administration Act 1953. These require that such data are only used for the purpose of carrying out functions of the ABS. No individual information collected under the Census and Statistics Act 1905 is provided back to the Registrar or ATO for administrative or regulatory purposes. Any discussion of data limitations or weaknesses is in the context of using the data for statistical purposes, and is not related to the ability of the data to support the ABR or ATO's core operational requirements. Legislative requirements to ensure privacy and secrecy of this data have been followed. Only people authorised under the Australian Bureau of Statistics Act 1975 have been allowed to view data about any particular firm in conducting these analyses. In accordance with the Census and Statistics Act 1905, results have been confidentialised to ensure that they are not likely to enable identification of a particular person or organisation. 